\title{
Distribution, magnitudes, reactivities, ratios and diurnal patterns of volatile organic compounds in the Valley of Mexico during the MCMA $2002 \& 2003$ field campaigns
}

\author{
E. Velasco ${ }^{1, *}$, B. Lamb ${ }^{1}$, H. Westberg ${ }^{1}$, E. Allwine ${ }^{1}$, G. Sosa ${ }^{2}$, J. L. Arriaga-Colina ${ }^{2}$, B. T. Jobson ${ }^{3, * *}$, \\ M. L. Alexander ${ }^{3}$, P. Prazeller ${ }^{3}$, W. B. Knighton ${ }^{4}$, T. M. Rogers ${ }^{4}$, M. Grutter ${ }^{5}$, S. C. Herndon ${ }^{6}$, C. E. Kolb ${ }^{6}$, \\ M. Zavala ${ }^{7}$, B. de Foy ${ }^{7}{ }^{*}$, R. Volkamer ${ }^{8}$, L. T. Molina ${ }^{7,}$, and M. J. Molina ${ }^{8}$ \\ ${ }^{1}$ Laboratory for Atmospheric Research, Department of Civil and Environmental Engineering, Washington State University, \\ Pullman WA, USA \\ ${ }^{2}$ Laboratorio de Química de la Atmósfera, Instituto Mexicano del Petróleo, México D.F., México \\ ${ }^{3}$ Atmospheric Sciences. Battelle Pacific Northwest National Laboratory, Richland WA, USA \\ ${ }^{4}$ Department of Chemistry and Biochemistry, Montana State University, Bozeman MO, USA \\ ${ }^{5}$ Centro de Ciencias de la Atmósfera, Universidad Nacional Autónoma de México, México D.F., México \\ ${ }^{6}$ Center for Atmospheric and Environmental Chemistry, Aerodyne Research Inc., Billerica, MA, USA \\ ${ }^{7}$ Department of Earth, Atmospheric, and Planetary Sciences, Massachusetts Institute of Technology, Cambridge MA, USA \\ ${ }^{8}$ Department of Chemistry and Biochemistry, University of California, San Diego, USA \\ * now at: Molina Center for Energy and the Environment (mce2.org), La Jolla CA, USA \\ ** now at: Washington State University, Pullman WA, USA
}

Received: 7 July 2006 - Published in Atmos. Chem. Phys. Discuss.: 8 August 2006

Revised: 21 December 2006 - Accepted: 12 January 2007 - Published: 23 January 2007

\begin{abstract}
A wide array of volatile organic compound (VOC) measurements was conducted in the Valley of Mexico during the MCMA-2002 and 2003 field campaigns. Study sites included locations in the urban core, in a heavily industrial area and at boundary sites in rural landscapes. In addition, a novel mobile-laboratory-based conditional sampling method was used to collect samples dominated by fresh on-road vehicle exhaust to identify those VOCs whose ambient concentrations were primarily due to vehicle emissions. Four distinct analytical techniques were used: whole air canister samples with Gas Chromatography/Flame Ionization Detection (GC-FID), on-line chemical ionization using a Proton Transfer Reaction Mass Spectrometer (PTR-MS), continuous real-time detection of olefins using a Fast Olefin Sensor (FOS), and long path measurements using UV Differential Optical Absorption Spectrometers (DOAS). The simultaneous use of these techniques provided a wide range of individual VOC measurements with different spatial and temporal scales. The VOC data were analyzed to understand concentration and spatial distributions, diurnal patterns, origin and reactivity in the atmosphere of Mexico City. The VOC
\end{abstract}

Correspondence to: E. Velasco

(evelasco@mce2.org) burden (in ppbC) was dominated by alkanes (60\%), followed by aromatics (15\%) and olefins (5\%). The remaining $20 \%$ was a mix of alkynes, halogenated hydrocarbons, oxygenated species (esters, ethers, etc.) and other unidentified VOCs. However, in terms of ozone production, olefins were the most relevant hydrocarbons. Elevated levels of toxic hydrocarbons, such as 1,3-butadiene, benzene, toluene and xylenes, were also observed. Results from these various analytical techniques showed that vehicle exhaust is the main source of VOCs in Mexico City and that diurnal patterns depend on vehicular traffic in addition to meteorological processes. Finally, examination of the VOC data in terms of lumped modeling VOC classes and its comparison to the VOC lumped emissions reported in other photochemical air quality modeling studies suggests that some alkanes are underestimated in the emissions inventory, while some olefins and aromatics are overestimated.

\section{Introduction}

Volatile organic compounds (VOCs) play a key role in photochemical air quality in urban atmospheres. In the presence of sunlight and nitrogen oxides $\left(\mathrm{NO}_{\mathrm{x}}\right)$, VOCs oxida-

Published by Copernicus GmbH on behalf of the European Geosciences Union. 


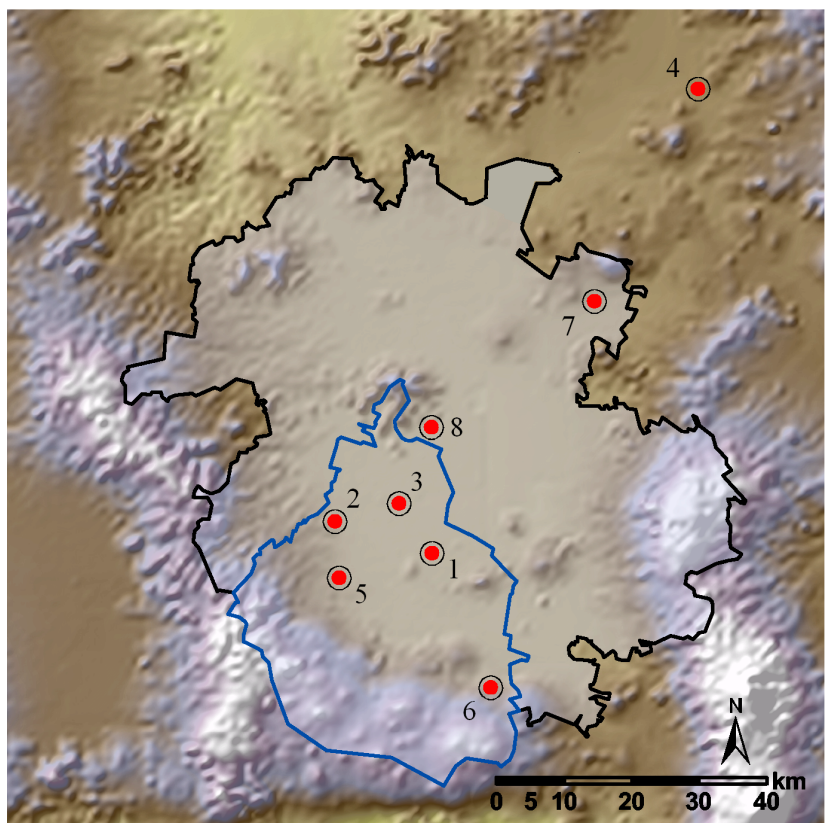

Fig. 1. Sampling sites during MCMA-2002 and MCMA-2003 field campaigns. Points indicate the location of the sampling sites and numbers correspond to the sites listed in Table 1 . The shadow limited by the black contour represents the boundary of the called "Mexico City Metropolitan Area", while the blue contour limits the Federal District. The Mexico City Metropolitan Area is more a political name than a topographic denomination to identify the extension of Mexico City.

tion produces secondary products including radicals (e.g., hydroxyl, hydroperoxy, organoperoxy), oxygenated organics (e.g., aldehydes, ketones, acids, nitrates, peroxides), and inorganics (e.g., carbon monoxide, ozone, hydrogen peroxide, nitric acid) (Finlayson-Pitts and Pitts, 1997). It has been demonstrated that many of these secondary compounds may have direct health impacts (Evans et al., 2002, and references therein), and that some individual VOCs are extremely toxic pollutants (e.g., the carcinogens benzene and 1-3-butadiene).

Mexico City with a population of 19 million is a good example of a megacity with severe air pollution problems. It is situated in the Valley of Mexico and is the capital city of a developing country. Mexico City is in the subtropical zone and at high altitude which makes combustion processes less efficient, leading to enhanced VOC emissions. Mexico City's high altitude $(\sim 2240 \mathrm{~m})$ and low latitude $\left(19^{\circ} 25^{\prime} \mathrm{N}\right)$, result in subtropical weather and intense solar radiation that accentuate the VOC evaporative emissions from a variety of sources such as storage and distribution of gasoline, solventbase cleaning, painting, and industrial processes. However, the main contributors to high VOC concentrations in Mexico City are the extensive presence of aged industrial operations (more than 53000 industries) and a relatively old vehicle fleet (more than 3.5 million vehicles with an average age of $\sim 9$ years). The elevated anthropogenic emissions, the intense solar radiation and area's topography with mountains to the west, east and south of the valley (see Fig. 1) produce elevated levels of photochemical pollutants on a daily basis (Molina and Molina, 2002).

Many researchers have addressed the VOC pollution problem in Mexico City. Ambient VOC concentrations have been evaluated since the early 90's (Raga et al., 2001 and references therein). All of these studies have consistently reported high concentrations of propane, butane and other low molecular weight alkanes, which have been attributed to liquefied petroleum gas (LPG) leakage during handling, distribution and storage. LPG is the main fuel for cooking and water heating in Mexican households. High ambient concentrations of photochemical reactive VOCs, such as olefins and aromatics, have been reported as well (Mugica et al., 2002a; Arriaga et al. 1997). These two VOC groups have been identified as the main species responsible for the ozone and secondary organic aerosol (SOA) formation in Mexico City (Gasca et al., 2004; Mugica et al., 2002a). High levels of aromatic hydrocarbons, particularly of toluene, benzene and xylenes, have been detected in different microenvironments and associated with diverse public transport systems in Mexico City (Shiohara et al., 2005; Gomez-Perales et al., 2004; Cruz-Nuñez et al., 2003; Bravo et al., 2002; Ortiz et al., 2002; Meneses et al., 1999).

From source apportionment studies, it has been determined that motor-vehicles, especially gasoline-powered vehicles, are the main source of aromatic hydrocarbons (Mugica et al., 2003). Emissions profiles for on-road motorvehicles have been obtained from tunnel studies (Mugica et al., 1998). Schifter et al. (2003) estimated on-road emissions of total hydrocarbons using remote sensors, and recently Zavala et al. (2006) and Rogers et al. (2006) quantified mobile emissions of benzene, toluene, formaldehyde and acetaldehyde via mobile laboratory "chase" experiments for real on-road conditions. However, vehicular emissions in Mexico City are still uncertain due to the lack of reliable fleet emission factors and daily activity levels (Gakenheimer et al., 2002). VOC emission profiles are also available for food cooking, asphalt application and painting operations, among other types of sources in Mexico City (Vega et al., 2000; Mugica et al. 2001a). The biogenic component in the VOC emission burden has been estimated to contribute no more than 7\% in the Valley of Mexico (Velasco, 2003).

During the last decade, a number of policies and actions have been enacted to decrease VOC emissions in Mexico City, among them, the installation of vapor recovery systems in fuel service stations, the banning of heavy fuel oil, the phasing out of leaded gasoline, the availability of diesel with reduced sulfur content and the substantial reduction of olefins, as well as benzene and other aromatic hydrocarbon content in gasoline. Arriaga-Colina et al. (2004) reported that, as result of these emission control measures, ambient VOC concentrations have stabilized and possibly decreased 
in the last 10 years, despite the growth in the vehicular fleet and other activities. However, ambient VOC levels still remain high and contribute to the exceedences of the national air quality standard for ozone on $70 \%$ of the days each year (110 ppb/1 $\mathrm{h}$ average; GDF, 2004).

Although some advances have been achieved, it is clear that a better understanding of photochemical pollution in the complex urban ecosystem of Mexico City is needed to support effective air quality emission control strategies. In this context, a number of US and Mexican institutions and agencies participated in the Mexico City Metropolitan Area 2002 and 2003 (MCMA-2002 \& MCMA-2003) field campaigns. MCMA-2002 was an exploratory campaign performed in February 2002, and MCMA-2003 was an intensive five-week field study during April and May, 2003. The goals of both field studies were to update and improve the emissions inventory of Mexico City, and to gain a better understanding of the chemistry and transport processes driving atmospheric pollution in the valley. As part of the effort to meet these goals, a wide array of VOC measurements was conducted at airshed boundary sites, central urban core sites, and downwind urban receptor sites. Four different analytical methods were used: VOC speciation by Gas Chromatographic analysis using Flame Ionization Detection (GC-FID), olefin detection with a Fast Olefin Sensor (FOS), determination of a number of oxygenated and aromatic VOCs by Proton Reaction Transfer Mass Spectroscopy (PTR-MS), and measurements of selected VOCs using Differential Optical Absorption Spectroscopy (DOAS). Key aspects of these VOC measurements were the large number of individual species measured under a variety of spatial and temporal scales employed in the measurements.

This manuscript presents a summary of results from the different VOC measurements in terms of the distribution, magnitudes, and diurnal patterns of selected VOCs. Ratios of individual VOC species are used to characterize different sites, to investigate the relative reactivity of different species and to determine their origins through comparisons with source signatures, in particular with vehicle exhaust profiles. In addition, the ambient VOC data have been compared to the lumped VOC emissions classes reported by West et al. (2004) to model the photochemical processes in the atmosphere of Mexico City. It has been suggested that VOC emissions are underestimated in the official emissions inventory by a factor of 3 from analysis of the $\mathrm{VOC} / \mathrm{NO}_{\mathrm{x}}$ ratio (Arriaga-Colina et al., 2004) and from ozone modeling exercises (West et al., 2004). However, eddy covariance flux measurements of selected VOCs during the MCMA-2003 campaign suggest that for the VOC classes measured, the VOC emissions reported in the emissions inventory are generally correct (Velasco et al., 2005).

\section{Monitoring sites}

During the MCMA-2002 study, five sites were selected for measuring ambient VOCs with instantaneous canister samples. For the MCMA-2003 study, two 2002 sites were excluded and three new sites were added, and diverse measurement techniques were implemented. Figure 1 shows a map of the Valley of Mexico indicating the monitoring sites where VOC measurements were performed in both campaigns. Overall, eight sites were employed; four locations were urban sites with different mixtures of commercial, residential, and light industrial activity (La Merced, Constituyentes, Pedregal and CENICA), one location was in an industrial section of the city (Xalostoc), and three locations were boundary sites in rural areas (La Reforma, Teotihuacan and Santa Ana Tlacotenco). Table 1 lists a summary of these sites and VOC measurement techniques used during the MCMA-2002 and MCMA-2003 field campaigns.

\section{Instrumentation}

3.1 Gas chromatography separation and flame ionization detection (GC-FID)

Ambient VOC samples were collected from all monitoring sites in Summa ${ }^{\circledR}$ electro-polished stainless-steel canisters. During the MCMA-2002 study, 46 samples were filled instantaneously, while for the MCMA-2003 study, 184 samples were collected in periods of $30 \mathrm{~min}, 1$ and $3 \mathrm{~h}$ using automated samplers. The different duration of the sampling periods was due to the specific sampling objectives at each site. From both studies, $64 \%$ of the samples were collected during the morning rush traffic period (6:00 to 9:00 h) when VOC concentrations are strongly related to traffic emissions and before photochemical processing has started. The remaining samples were collected during the late morning and early afternoon hours.

Canister samples were collected and analyzed by two different research groups: Washington State University (WSU) and the Mexican Petroleum Institute (IMP). WSU collected and analyzed $78 \%$ of the samples. During the MCMA-2003 study, WSU collected all its samples with a XonTech, Inc. Air Sampler model 910PC. Half of the samples were analyzed on-site within $24 \mathrm{~h}$ of collection; the remainder samples were returned to WSU for analysis. IMP collected samples only in 2003 using an AVOCS Anderson Automated Sampler with a Viton diaphragm pump. Both groups analyzed their samples using methodology similar to the US EPA compendium methods TO-14/15 (USEPA, 1999a). The GC analysis utilized cryogenic pre-concentration by drawing air from the canisters through a stainless-steel loop containing glass beads (60/80 mesh) and cooled to liquid oxygen temperature. WSU employed a Hewlett-Packard 6890 Series chromatograph. The GC was equipped with a $30-\mathrm{m}$ fused 
Table 1. Description of the VOC monitoring sites during the MCMA-2002 (7-24 February) and 2003 (1 April-5 May) field campaigns. The numbers in parenthesis in the column of methods indicate the number of collected samples in canisters or the number of days monitored by PTR-MS, DOAS or FOS.

\begin{tabular}{|c|c|c|c|c|}
\hline Site \# & Site and position & Year & Site description & Method \\
\hline 3 & $\begin{array}{l}\text { La Merced } \\
\left(\mathrm{N} 19.424^{\circ}, \mathrm{W} 99.119^{\circ}\right)\end{array}$ & 2003 & $\begin{array}{l}\text { Central city section composed by a mix of residences, } \\
\text { small and medium commerce, light industries and a } \\
\text { busy market. } \\
\text { Heavy traffic on paved roads with private cars, light- } \\
\text { duty vehicles and modern heavy-duty diesel buses. }\end{array}$ & $\begin{array}{l}\text { Canister sampling and } \\
\text { GC-FID analysis (41). } \\
\text { PTR-MS (3). } \\
\text { DOAS (30). }\end{array}$ \\
\hline 5 & $\begin{array}{l}\text { Pedregal } \\
\left(\mathrm{N} 19.325^{\circ}, \mathrm{W} 99.204\right)\end{array}$ & $2002 \& 2003$ & $\begin{array}{l}\text { Southwestern suburban neighborhood with paved resi- } \\
\text { dential roads lightly traveled. } \\
\text { This site is in the prevailing downwind direction from } \\
\text { the center of the city. }\end{array}$ & $\begin{array}{l}\text { Canister sampling and } \\
\text { GC-FID analysis (66). } \\
\text { PTR-MS (4). }\end{array}$ \\
\hline 6 & $\begin{array}{l}\text { Santa Ana Tlacotenco } \\
\left(\mathrm{N} 19.177^{\circ}, \mathrm{W} 98.99^{\circ}\right)\end{array}$ & 2003 & $\begin{array}{l}\text { Rural site to the southwest of Mexico City, close to the } \\
\text { gap in the mountains at Amecameca. } \\
\text { Paved and unpaved roads with minimum traffic. }\end{array}$ & $\begin{array}{l}\text { Canister sampling and } \\
\text { GC-FID analysis (13). } \\
\text { PTR-MS (3). }\end{array}$ \\
\hline 7 & $\begin{array}{l}\text { Teotihucan } \\
\left(\mathrm{N} 19.688^{\circ}, \mathrm{W} 98.870^{\circ}\right)\end{array}$ & 2002 & $\begin{array}{l}\text { Northern upwind boundary site of Mexico City with } \\
\text { pollution influence from a large power plant and large } \\
\text { industries around the region. }\end{array}$ & $\begin{array}{l}\text { Canister sampling and } \\
\text { GC-FID analysis ( } 7) .\end{array}$ \\
\hline
\end{tabular}

silica DB-1 column $(0.32 \mathrm{~mm}$ i.d. and $1 \mu \mathrm{m}$ film thickness $)$ with a $2 \mathrm{ml} \mathrm{min}^{-1}$ carrier flow. Prior to sample injection, the oven was cooled to $-50^{\circ} \mathrm{C}$. During analysis, the oven temperature was raised at $4^{\circ} \mathrm{C} \mathrm{min}-1$ to a final temperature of $150^{\circ} \mathrm{C}$. The total analysis time was approximately one hour. Detector response was calibrated with NIST traceable 2,2dimethylbutane standard. A detection limit of $20 \mathrm{pptC}$ was determined. Individual species were identified by retention times.

IMP conducted their analysis using a Hewlett-Packard 5890 Series II chromatograph containing a 60-m Quadrex fused silica glass capillary column with a phase designation 007 series methyl-silicone $(0.32 \mathrm{~mm}$ i.d. and coated with a $1 \mu \mathrm{m}$ film thickness) at a flow of $2 \mathrm{ml} \mathrm{min}^{-1}$. The oven temperature started at $050^{\circ} \mathrm{C}$ and was heated up to $200^{\circ} \mathrm{C}$ at a rate of $8^{\circ} \mathrm{Cmin}^{-1}$. The FID response was calibrated with a certified high-purity propane standard from Praxair. The detection limit was determined to be $1 \mathrm{ppbC}$. Individual species were identified by retention times using a mixture of 55 hydrocarbons (Scott Specialty Gases NIST Traceable), and a certified mixture of 33 halogen-containing compounds (Spectra Gases, with 10\% analytical accuracy).

\subsection{The Proton Transfer Reaction Mass Spectrometry (PTR-MS)}

The Proton Transfer Reaction Mass Spectrometry identifies VOCs in ambient air as their molecular mass plus one. This 
technique creates ions by transferring a $\mathrm{H}^{+}$from $\mathrm{H}_{3} \mathrm{O}^{+}$to the VOCs followed by mass spectroscopy detection of the product ions (Lindinger et al., 1998). The PTR-MS does not employ a column, so response times are short (seconds) and automated, continuous measurements can be made over extended periods of time. Specificity in the PTR-MS is achieved by the soft ionization (minimal fragmentation) and the response is limited to species with proton affinity greater than water. In cases where several VOCs produce the same $\mathrm{M}+1$ ion, it is not possible to quantify individual species. For example, the signal at mass 121 ( $\mathrm{C}_{3}$-benzenes) is comprised of i- and n-propylbenzene, three ethyltoluene and three trimethylbenzenes isomers. Validation of PTR-MS measurements have been performed by de Gouw et al. (2003) and Warneke et al. (2003) to determine the set of VOCs that are suitable for measurement with this technique.

During the MCMA-2003 field campaign, two PTR-MS instruments were used. One was operated at the CENICA site by the Pacific Northwest National Laboratory (PNNL), and the second PTR-MS instrument, belonging to Montana State University (MSU), was housed in a mobile laboratory for on-road vehicle emissions studies and both fixed site and mobile ambient pollutant measurements (Kolb et al., 2004; Herndon et al., 2005; Zavala et al., 2006; Rogers et al., 2006). During selected periods, the mobile laboratory was employed as a fixed monitoring station at La Merced, Santa Ana Tlacotenco and Pedregal sites. This manuscript presents only PTR-MS measurements from fixed-sites. The species monitored by PTR-MS included benzene, toluene, styrene, $\mathrm{C}_{2}$-benzenes, $\mathrm{C}_{3}$-benzenes, naphthalene, phenol, cresols, methanol, acetaldehyde, acetone and acetonitrile. The $\mathrm{C}_{2}$ benzenes are represented by mass 107 , which has contributions from ethylbenzene, o-, m- \& p-xylene, and benzaldehyde (de Gouw et al., 2003).

Both of the PTR-MS instruments were calibrated in the field using a multi-component gas standard containing the species reported here. The calibration standard was diluted with humidified zero air in order to generate a multipoint calibration curve from 1 to $50 \mathrm{ppbv}$. Calibrations were performed every 2-3 days. The instrument background was automatically recorded every $3 \mathrm{~h}$ by switching the sample flow to a humid zero air stream. Zero air was continuously generated by passing ambient air through a Pt-catalyst trap heated to $300^{\circ} \mathrm{C}$. Background count rates were subtracted from the ambient data.

\subsection{Fast Olefin Sensor (FOS)}

Continuous real-time measurements of olefin concentrations were made at the CENICA site during the MCMA-2003 study by WSU using a FOS. The FOS is a fast isoprene sensor (Guenther and Hills, 1998) based on chemiluminescence that occurs when an olefinic bond reacts with ozone. The chemiluminescent response varies considerably for individual olefins. In an urban atmosphere where numerous olefins are present, it is necessary to evaluate the FOS response to as many olefins as possible. For Mexico City, we determined response characteristics for five olefins (propylene, ethylene, isoprene, 1-butene and 1-3 butadiene). Since NO levels are known to be high in the Mexico City atmosphere, we investigated potential interferences due to its reaction with ozone. Nitric oxide gave no response in this test. Response results for the olefins are shown in Table 2 along with their corresponding relative sensitivities to propylene. It was found that the FOS is more sensitive to 1-3-butadiene and isoprene than to propylene; however, their ambient concentrations were much lower than the ambient levels of propylene. In contrast, species with a lower sensitivity than propylene, but with high concentrations in urban atmospheres (e.g., ethylene) can produce large signals.

During the campaign, the FOS was calibrated 3 times per day using dilutions from a propylene standard (Scott Specialty Gases, $10.2 \mathrm{ppm}, \pm 5 \%$ certified accuracy). The linear slope of instrument response versus propylene concentration and the zero level exhibited relatively little drift during the study period: $14 \%$ and $9 \%$, respectively.

\subsection{Differential Optical Absorption Spectroscopy (DOAS)}

Two research grade, long path DOAS instruments were installed at the CENICA site during the MCMA-2003 study. DOAS is based on the UV-molecular absorption of atmospheric gases and measures continuously concentrations of a number of trace gases averaged over a long optical path. In brief, for these two DOAS, light from broadband UV/vis light sources (Xe-short arc lamps) were projected into the open atmosphere onto a distant array of retro reflectors, which folded the light paths back into the instruments where spectra were recorded using Czerny-Turner type spectrometers coupled to 1024-element PDA detectors. One DOAS measured formaldehyde and glyoxal, and its results are discussed elsewhere (Volkamer et al., 2005). The second DOAS measured a larger number of VOCs: formaldehyde, benzene, toluene, m-xylene, p-xylene, mono-substituted alkylbenzenes $\left(\mathrm{C}_{2}\right.$ and higher), phenol, p-cresol, styrene, naphthalene and benzaldehyde. These VOCs were measured by observing their unique specific narrow-band $(<5 \mathrm{~nm})$ absorption structures through a light path of $430 \mathrm{~m}$ (total $860 \mathrm{~m}$ ) at a height of $16 \mathrm{~m}$. Spectra were recorded by sequentially observing 40-nm wide wavelength intervals in the wavelength range between 240 and $375 \mathrm{~nm}$ at $0.2 \mathrm{~nm}$ FWHM spectral resolution. The time resolution of recording a full cycle of spectra varied between $30 \mathrm{~s}$ and $4 \mathrm{~min}$, depending on the abundance of UV-light absorbing ozone. Absorptions of atmospheric oxygen were eliminated using the interpolation approach of Volkamer et al. (1998), using oxygen column densities of $3.7 \times 10^{17}$ molecules $\mathrm{cm}^{-2}$ and $4.1 \times 10^{17}$ molecules $\mathrm{cm}^{-2}$, and updated evaluation routines. Reference spectra of aromatic compounds were recorded by introducing quartz-cuvettes filled with vapor into the light 
Table 2. Sensitivities, average concentrations measured during selected days throughout the MCMA-2003 campaign between 6 and 10 am by a canister sampling system and GC-FID analysis, FOS responses to those average concentrations, and relative sensitivities to propylene for six compounds.

\begin{tabular}{lcccc}
\hline Compound & $\begin{array}{c}\text { Sensitivity } \\
\left(\text { photons ppb }^{-1} \mathrm{~s}^{-1}\right)\end{array}$ & $\begin{array}{c}\text { Average conc., 6-10 am } \\
(\mathrm{ppb})\end{array}$ & $\begin{array}{c}\text { Average FOS response } \\
\left(\text { photons s}^{-1}\right)^{\mathrm{c}}\end{array}$ & $\begin{array}{c}\text { Relative sensitivity } \\
\text { to propylene }^{\mathrm{d}}\end{array}$ \\
\hline Propylene & 25.4 & 7.50 & 191 & 1.00 \\
Isoprene & 74.7 & 0.304 & 23 & 2.94 \\
Ethylene & 17.7 & 20.7 & 366 & 0.70 \\
1-3 butadiene & 49.8 & 0.791 & 39 & 1.96 \\
1-butene & 7.9 & $3.90^{\mathrm{a}}$ & 31 & 0.31 \\
NO & $\sim 0.0$ & $61.2^{\mathrm{b}}$ & 0 & $\sim 0.0$ \\
\hline
\end{tabular}

a As i-butene

$\mathrm{b}$ From continuous monitoring during the entire campaign

${ }^{c}$ Average response $=($ sensitivity $)($ average conc $)+($ zero value $)$

$\mathrm{d}$ Relative sensitivity $=($ compound sensitivity $) /($ propylene sensitivity $)$

beam, and these spectra were calibrated to the absorption cross-sections (Etzkorn et al., 1999). The mean detection limits in ppbv were: 5 (formaldehyde), 1 (benzene, toluene, m-xylene), 0.3 (p-xylene), 1.8 (ethylbenzene-equivalents), 0.5 (styrene), 0.06 (phenol, p-cresol), 0.2 (benzaldehyde), and 0.08 (naphthalene).

Also, during the MCMA-2003 study the National Autonomous University of Mexico (UNAM) deployed a commercial DOAS system (Opsis, Model AR500) at the La Merced site to measure ambient concentrations of benzene and toluene along a 426-m optical path. The transmitting and receiving telescopes were installed on top of two four-story buildings with the beam trajectory $20 \mathrm{~m}$ above the surface. The acquisition time was set to $5 \mathrm{~min}$. Concentrations of benzene and toluene were retrieved using the internal evaluation software of the instrument. The instrument response was corrected based on a multipoint calibration performed in the laboratory and adjusted for real temperature and pressure conditions. No humidity correction was applied. Prior to the measurements reported here, a reference spectrum (background) was stored for every spectral region used in the analysis using a calibration bench (Opsis CB100, RE060 and CA150) without gas cells installed. A wavelength precision test was also performed using a low-pressure mercury lamp (CA004). More details are provided by Grutter and Flores (2004).

\section{Ambient air inter-comparison of GC, PTR-MS and DOAS measurements for selected VOCs}

Table 1 shows that at $50 \%$ of the monitored sites, two or more different techniques were used to measure VOCs. This provides the opportunity to inter-compare data to verify that they yield consistent results. Figures $2 \mathrm{a}$ and $\mathrm{b}$ show time series of benzene and toluene mixing ratios measured by GC-FID (WSU), PTR-MS (MSU) and commercial DOAS (UNAM) at the La Merced site. Both figures show generally good temporal agreement for benzene and toluene. Some differences between concentration levels measured by DOAS and the other two methods are to be expected. The DOAS signal represents average concentrations over an open path distance of about $426 \mathrm{~m}$ while the PTR-MS and GC data are from measurements at a specific location. The PTR-MS technique is the most sensitive to transient plumes from close-by sources because it measures in real-time with very little temporal averaging. This feature can be seen in Fig. 2a where benzene concentrations determined by the PTR-MS are much more variable than those from DOAS or GC-FID. For example the hourly standard deviations of concentrations measured by the PTR-MS are twice those measured by DOAS. Furthermore, it is evident in this figure that the GC results agree better with the PTR-MS than with DOAS which is expected since both GC and PTRMS were point measurements at the same location.

During the afternoon hours the benzene concentrations measured by DOAS showed a peak that was not registered by the other two techniques. It is unusual to see a benzene peak in the 12-16:00 time period, when atmospheric photochemistry is at its highest rate. Also the relative decrease observed for toluene does not match that of benzene, indicating that the toluene to benzene ratio as calculated from the commercial DOAS data appears to be subject to diurnal variability. It is well known that Opsis DOAS measurements of benzene require an offset correction, which has been applied to the data. The reason for the high benzene values in the afternoon is not easily understood. Kim (2004) and Pinhua et al. (2004) have reported poor correlations between DOAS measurements of benzene and GC-FID measurements for urban environments.

The toluene time series shows better agreement among different techniques and a more normal urban pattern of high nighttime and early morning concentrations and much 

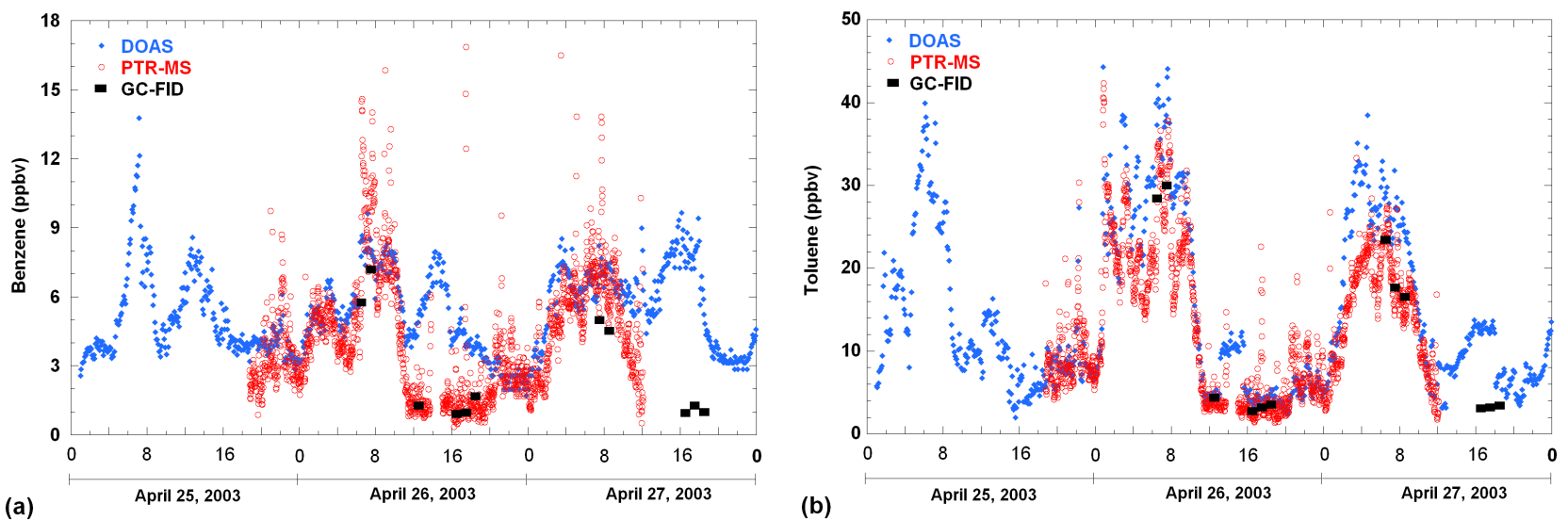

Fig. 2. Time series of benzene (a) and toluene (b) mixing ratios measured by DOAS, PTR-MS and GC-FID at the La Merced site. The resolution time for DOAS was $5 \mathrm{~min}$ and for PTR-MS $\sim 30 \mathrm{~s}$. PTR-MS points correspond to 1 min averages. Samples collected by canisters and analyzed by GC-FID correspond to $1 \mathrm{~h}$ averages. Short term spikes were commonly observed with PTR-MS indicating local sources.

lower levels during the midday period. Jobson et al. (2007) ${ }^{1}$ present a more detailed inter-comparison with the same three techniques at the CENICA site. They found that the level of agreement between point and long path techniques is influenced by wind direction, but in general terms they also found relatively good agreement between GC, PTR-MS and the research grade DOAS.

Figure 3 shows time series plots of $\mathrm{C}_{2}$-benzenes and $\mathrm{C}_{3}$ benzenes measured by the MSU PTR-MS together with GCFID samples collected during the same time periods at the Pedregal, Santa Ana Tlacotenco and La Merced sites. At La Merced and Pedregal sites, good agreement between methods for the two aromatic groups was observed. Temporal variability correlate well and GC-FID mixing ratios were always within the one standard deviation range of the PTRMS measurements, but the agreement was not as good at the Santa Ana Tlacotenco site. GC-FID $\mathrm{C}_{3}$-benzenes concentrations were quite often above the one standard deviation range of the PTR-MS concentrations. Note that concentrations at this site were one order of magnitude smaller than at the other sites. The agreement between GC and PTR-MS for benzene was not as good at the rural Santa Ana Tlacotenco site (not shown here) as at the urban sites. GC-FID measurements of benzene were always near the lower limit of the one standard deviation range of the PTR-MS concentrations. This difference is likely due to PTR-MS interferences from higher aromatics such as ethylbenzene. Partial fragmentation of mono-alkyl aromatics occurs in the PTRMS, producing a positive artifact for benzene measurements.

\footnotetext{
${ }^{1}$ Jobson, B. T., Alexander, M. L., Prazeller, P., Berkowitz, C. M., Westberg, H., Velasco, E., Allwine, E., Lamb, B., Volkamer, R., Molina, L. T. and Molina, M. J.: Intercomparison of volatile organic carbon measurements techniques and data from the MCMA 2003 field experiment, in preparation, 2007.
}

Jobson et al. (2007) ${ }^{1}$ determined an overestimation of $\sim 16 \%$ for PTR-MS measurements at the CENICA site. A comparison of the benzene/ethylbenzene ratio between the different sites shows that the ratio at Santa Ana Tlacotenco was low, indicating a higher presence of ethylbenzene than benzene in relation to urban sites. For the ambient concentrations of toluene, we found that PTR-MS and GC-FID measurements agreed closely at all three sites.

Analytical consistency was examined for the two GC techniques by collecting parallel samples using WSU and IMP canister samplers. WSU reported 58 hydrocarbons up to 10 carbons, while IMP quantified 104 VOCs up to 12 carbons, including oxygenated and halogenated species. The extra 47 species determined by IMP represented less than $10 \%$ of the total VOC burden. Halogenated species comprised about $2.5 \%$ of the total VOCs. Comparison of the analytical results for each of the 57 compounds during four different sampling periods showed a $\mathrm{VOC}_{\mathrm{WSU}} / \mathrm{VOC}_{\mathrm{IMP}}$ ratio between 0.9 and 1.10 .

A comparison of the FOS response to the sum of olefins as measured simultaneously with the canister sampling system suggests that the total olefin level detected by the FOS is larger than the sum of identified olefins from canister samples. The ratio between the sum of olefins measured by canisters and the FOS signal showed a median of 0.48. This suggests that $52 \%$ of olefins detected by the FOS remain unknown or that the use of propylene as the calibration standard does not adequately represent the urban olefin mix. Additional laboratory studies are needed to resolve this uncertainty. However, it can be affirmed that the FOS measures a mix of VOCs responding as propylene and can be used to provide a continuous and fast response measurement of the olefinic VOC mix in an urban atmosphere. 

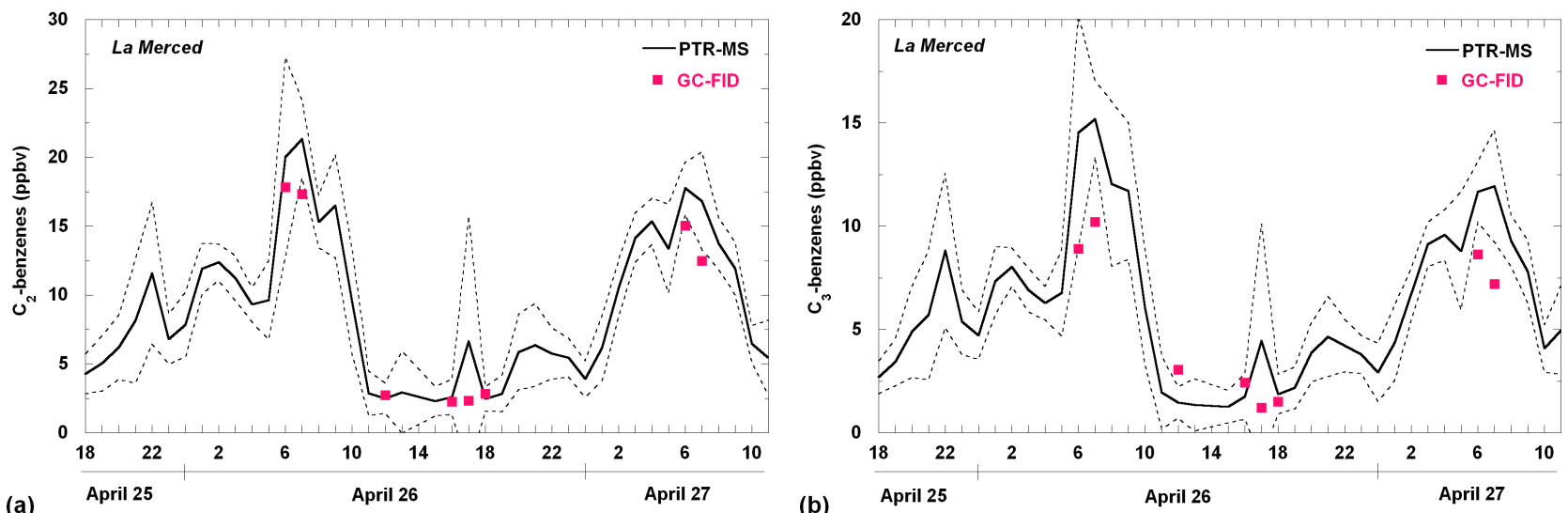

(a)
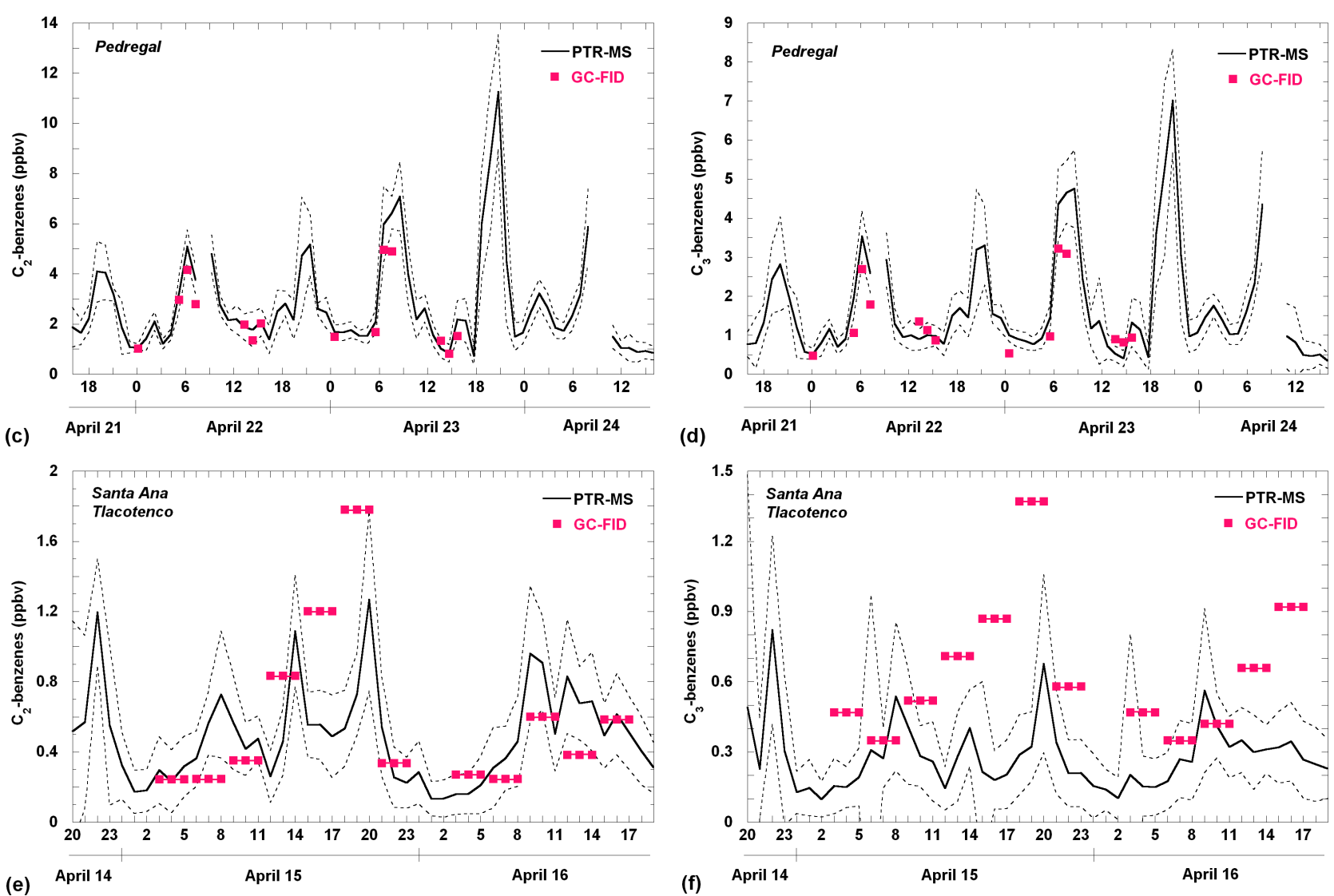

Fig. 3. Time series of $\mathrm{C}_{2}$-benzenes and $\mathrm{C}_{3}$-benzenes measured by the PTR-MS together with GC-FID samples collected in parallel at La Merced (a, b), Pedregal (c, d) and Santa Ana sites (e, f). PTR-MS concentrations represent hourly averages. GC-FID samples were collected in hourly periods at La Merced and Pedregal sites, and in 3-hours periods at Santa Ana Tlacotenco. The dashed lines indicate \pm 1 standard deviation of the PTR-MS concentrations.

\section{Results and discussion}

\subsection{Diurnal patterns of various VOCs at selected sites}

Although the VOC time series shown in Figs. 2, and 3 only cover a few days, in addition to the diurnal patterns of olefins measured by FOS in Fig. 4 and four aromatic species mea- sured by DOAS in Fig. 5 at the CENICA site, they provide some insight concerning the diurnal pattern of VOCs at sites with different characteristics in the Valley of Mexico. For example, at the La Merced and CENICA sites, concentrations of benzene, toluene, $\mathrm{C}_{2}$-benzenes and $\mathrm{C}_{3}$-benzenes reach their highest level during the morning rush hour. The mixing height in Mexico City grows rapidly as soon as solar 


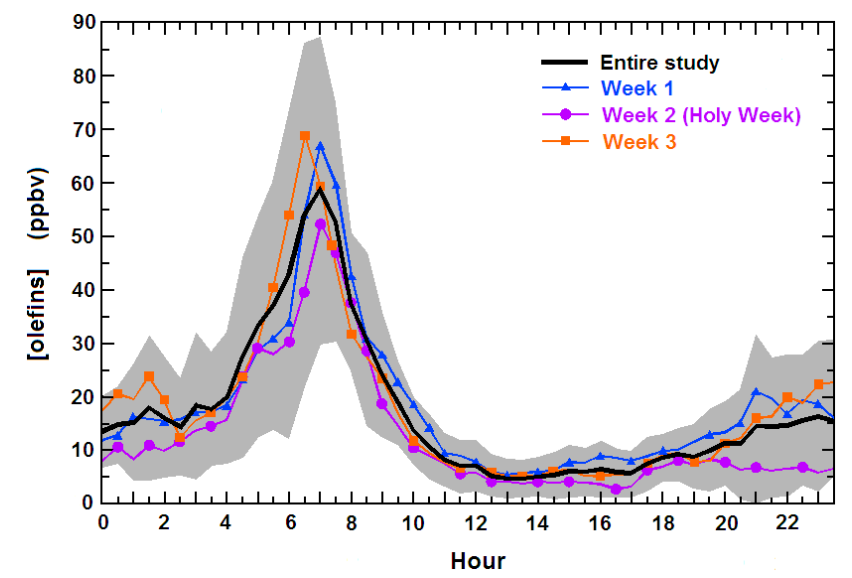

Fig. 4. Average diurnal pattern of the olefinic mixing ratio (as propylene) detected by the FOS for 23 days during the MCMA2003 study (black line) and for individual weeks (week 1: 7-13 April, week 2: 14-20 April, and week 3: 21-27 April) at the CENICA site. The gray shadow represents the one standard deviation range, and gives and indication of the day-to-day variability in each phase of the daily cycle.

heating of the surface begins and drops abruptly around sunset (Whiteman et al., 2000). De Foy et al. (2005) found surface temperature inversions below $500 \mathrm{~m}$ for most nights of the campaign, and growth of the boundary layer up to a maximum of $4000 \mathrm{~m}$ during the day. Emissions due to vehicle traffic begin around 6:00 $\mathrm{h}$ and stay high during the day. This explains the increase in concentrations during the morning which reach a maximum around 9:00 after sunrise, but before the mixing layer has started to grow. Once the mixed layer begins to deepen, the concentrations drop until the evening.

It is interesting to compare the relative strengths of the morning and evening VOC concentration peaks at La Merced or CENICA with those at Pedregal. At La Merced and CENICA, the morning peak is very strong and in the afternoon, the VOC peak is barely perceptible. At Pedregal, the morning and afternoon peaks are of equal magnitude, but overall levels are lower than at La Merced by around a factor of three. Traffic counts performed during the MCMA-2003 campaign on avenues close to the two sites indicated that at La Merced traffic stays high from 6:00 h until late evening, whereas at Pedregal there is the typical morning and afternoon rush hour peaks. Meteorological analysis by de Foy et al. (2005) showed that in the basin, which includes La Merced, winds are very calm at sunrise leading to minimal horizontal dispersion. By sunset, wind speeds have reached a maximum leading to substantial dilution. At the Pedregal site, there are slope flows from the basin rim during the early morning hours leading to greater dispersion than at the $\mathrm{La}$ Merced site. In the evening, there is transport away from urban areas and out of the valley.
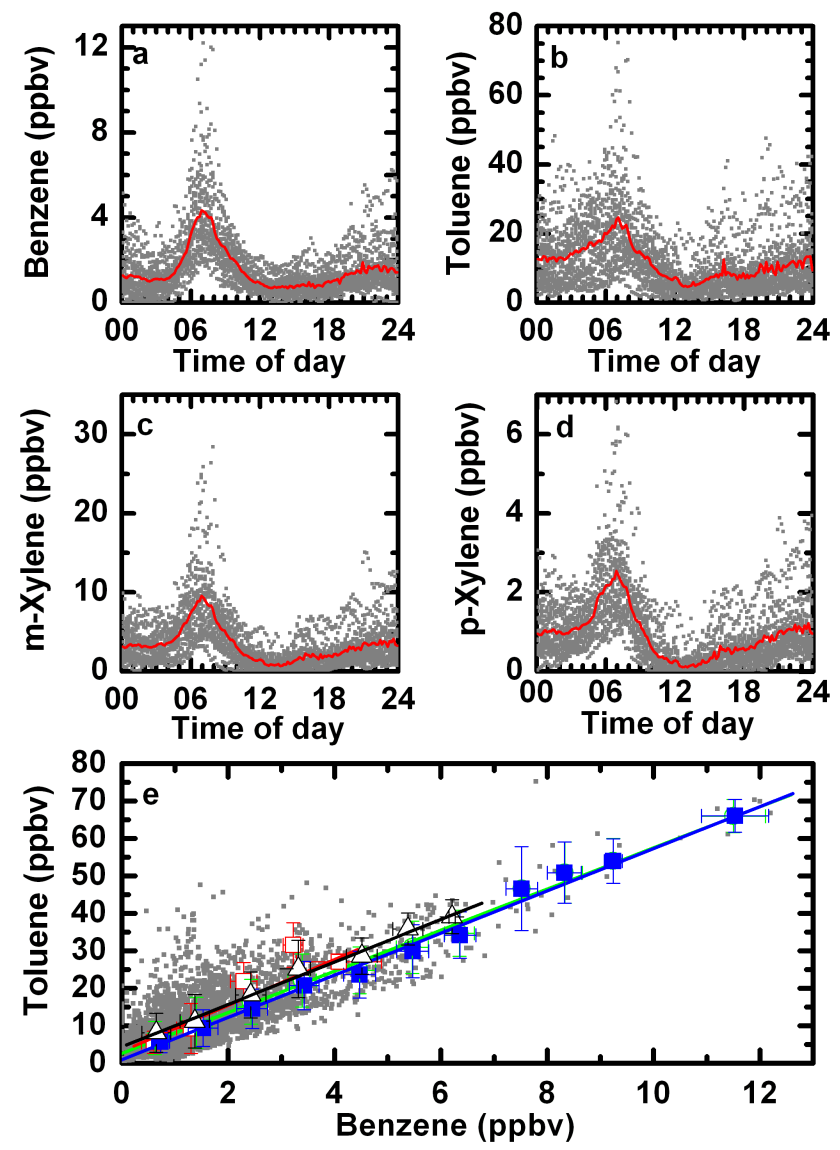

Fig. 5. Diurnal patterns of benzene (a), toluene (b), m-xylene (c), and p-xylene (d) measured by DOAS at the CENICA site. Grey dots indicate individual measurements and red lines indicate the diurnal profile averaged over all data. Panel (e) shows the toluene-benzene correlations. The correlations were averaged into bins for different time periods: blue solid squares for morning (5-12:00 h), red open squares for afternoon (12-20:00 h), black open triangles for nighttime (20-5:00 h), and green circles all data. The linear regression parameters of these data-subsets are listed in Table 3.

Santa Ana Tlacotenco is a rural site on the edge of the urban area on mountain slopes (see Fig. 1) surrounded by cactus fields. It is located close to the Chalco pass in the southeast part of the basin where a low level jet forms in the afternoon bringing in clean cool air from the Valley of Cuautla (Doran and Zhong, 2000). Analysis of this feature during the MCMA-2003 field campaign shows that on April 15 , southerly winds blew the urban plume towards the site, and the jet formed around 16:00 h. This explains the three peaks observed in the diurnal profile for that day. There is a small rush hour peak due to local emissions. These are swiftly diluted, but concentrations rise again when the urban plume reaches the site. The low level jet brings in clean air and concentrations rise again after its passage as winds calm and the mixing layer has collapsed. This is in agreement with Raga et al. (1999) who estimated a 3-hour transport time 
Table 3. Toluene / benzene ratio as measured by DOAS at the CENICA site. The numbers at the right of the \pm symbol indicate one standard deviation.

\begin{tabular}{lccc}
\hline Time & Offset & Slope & $\mathrm{R}^{2}$ \\
\hline 5:00-12:00 h & $1.0 \pm 2.4$ & $5.6 \pm 0.4$ & 0.996 \\
12:00-20:00 h & $3.2 \pm 3.3$ & $6.1 \pm 1.0$ & 0.910 \\
20:00-5:00 h & $4.4 \pm 4.4$ & $5.7 \pm 1.0$ & 0.992 \\
All data & $2.6 \pm 3.2$ & $5.5 \pm 0.5$ & 0.995 \\
\hline
\end{tabular}

from the urban area to the basin perimeter. In general, local concentrations of benzene, toluene, $\mathrm{C}_{2}$-benzenes and $\mathrm{C}_{3}$ benzenes were lower than $1 \mathrm{ppbv}$ during the entire diurnal cycle. However, a number of spikes with higher concentrations were observed, at least one of which, in the evening of April 15th, was due to a neighboring trash fire.

The FOS provided an alternative method to measure concentrations of olefins in real time at the CENICA site during the MCMA-2003 study. As shown in Fig. 4, the diurnal average pattern of olefinic VOCs detected by the FOS exhibits a similar pattern to what would be expected for typical pollutants emitted by mobile sources (INE, 2000). The highest olefin concentrations were measured at 7:00 h and ranged from 30 to $87 \mathrm{ppbv}$, averaging $58 \mathrm{ppbv}$. This morning peak is attributed to the release of anthropogenic emissions into a shallow mixed layer as the work day begins followed by a rapid dilution as the sun warms the surface and expands the mixed layer, in addition to the onset of the atmospheric photochemistry. Low olefin concentrations were observed during the afternoon, with an average of $6.6 \mathrm{ppbv}$, when dilution through the deep mixed layer was large, the photochemical reactions contribute to alkene destruction and emissions were reduced compared to morning periods. The diurnal olefin pattern was relatively constant during the entire study. The MCMA-2003 field campaign included the Holy Week (1420 April), a period in which the vehicular traffic is reduced as many of the city residents leave for the holiday period. By taking measurements before, during and after this period, we expected to obtain data to help determine the influence of vehicular emissions upon atmospheric pollution. The FOS reported a small difference of 6 ppbv in the olefin mixing ratio during the early morning peak between Holy Week and the other two measurement weeks.

Figure 5 shows the diurnal profiles of benzene, toluene, $\mathrm{m}$ xylene and p-xylene measured by DOAS at the CENICA site. Overall, the diurnal profiles of all compounds are well correlated. It is interesting to note, that the toluene to benzene ratio at the CENICA site is independent from the time of day (see Fig. 5e). The slope of a linear regression to subsets of data during the morning, evening and at night are constant to within $10 \%$ (see Table 3), reflecting negligible photochemical aging due to the dominant influence of fresh emissions on atmospheric concentrations also during the day. The $\mathrm{m}$ xylene to p-xylene ratio was determined as 3.5.

A comprehensive analysis of the diurnal patterns of benzene and toluene measured at La Merced by DOAS is provided by Grutter and Flores (2004), as well as for a few hydrocarbons using a Fourier Transform Infrared Spectrometer (Grutter et al., 2003). Jobson et al. (2007) ${ }^{1}$ describe in detail the diurnal patterns of a number of VOCs measured by PTR-MS at the CENICA site.

\subsection{Ambient mixing ratios and hydrocarbon reactivity}

The highest ambient mixing ratios of VOCs in the atmosphere of Mexico City occur during the morning rush hours $(6: 00$ to $9: 00 \mathrm{~h})$. An analysis of the canister sampling from the four urban monitoring sites (Pedregal, La Merced, CENICA and Constituyentes) during this morning period provides a description of the VOC species that contribute to photochemical ozone and haze production in Mexico City. On the basis of average concentrations, the 10 most abundant VOCs for those sites were in decreasing order: propane ( $127 \pm 63 \mathrm{ppbv}), \mathrm{n}$-butane $(50 \pm 25)$, ethylene $(20 \pm 11)$, i-butane $(18 \pm 9)$, ethane $(17 \pm 11)$, i-pentane $(17 \pm 9)$, toluene (13 \pm 9$)$, acetylene (13 \pm 8$)$, n-pentane ( $7 \pm 4)$, and methyl tertiary-butyl ether (MTBE) $(7 \pm 4)$. The numbers at the right of the \pm symbol indicate the one standard deviation. For some species, in particular aromatics, the standard deviation showed high values in urban and rural sites. Consider they represent the average concentration of different sites with similar characteristics and that the study embraced a short number of samples. In general, VOC mixing ratios observed in this study are slightly lower than those reported in previous studies (Arriaga et al., 1997; Mugica et al., 2002a), which is consistent with the conclusion of Arriaga et al. (2004) that ambient VOC concentrations have stabilized or possibly started to decrease. The elevated levels of low molecular weight alkanes measured here are consistent with those reported in the first VOC study in Mexico City (Blake and Sherwood, 1995), and they are attributable mainly to the widespread use of LPG as cooking and water heating fuel.

It is useful to examine the VOC distribution in an urban area in terms of reactivity with the hydroxyl radical $(\mathrm{OH})$, which in fact represents the contribution of each VOC species to the $\mathrm{OH}$ loss rate. The $\mathrm{OH}$ loss rate is a measure of the initial peroxy radical formation rate, which is frequently the rate-limiting step in ozone formation. The actual amount of ozone produced by a given hydrocarbon depends on their particular oxidation mechanism, the abundance of other hydrocarbons, and $\mathrm{NO}_{\mathrm{x}}$ concentrations (Carter, 1994). While realizing that this approach does not account for the full atmospheric chemistry of the compounds considered, it provides a useful approximation of their relative contributions to daytime photochemistry. For this purpose, Table 4 lists the major hydrocarbons in the atmosphere of the Valley of Mexico by reactivity with $\mathrm{OH}$ along with their average am- 
Table 4. OH reactivity and average ambient concentrations of major NMHC measured during the MCMA-2002 and 2003 studies at urban (Pedregal, La Merced, CENICA and Constituyentes), rural (Santa Ana Tlacotenco, Teotihuacan and La Reforma) and industrial (Xalostoc) sites of the Valley of Mexico. Data correspond to the morning rush hours (6:00 to 9:00 h). The numbers at the right of the \pm symbol indicate one standard deviation.

\begin{tabular}{|c|c|c|c|c|c|c|c|c|}
\hline \multirow[t]{2}{*}{ Species } & \multirow[t]{2}{*}{ Group } & \multirow[t]{2}{*}{$\mathrm{OH}$ reaction rate coeff.* } & \multicolumn{3}{|c|}{$\mathrm{OH}$ reactivity ${ }^{\S}\left(\mathrm{s}^{-1}\right)$} & \multicolumn{3}{|c|}{ Ambient concentration (ppbv) } \\
\hline & & & Urban & Rural & Industrial & Urban & Rural & Industrial \\
\hline Ethylene & olefin & 8.52 & $4.26 \pm 2.25$ & $0.59 \pm 0.64$ & $6.72 \pm 4.01$ & $20.33 \pm 10.75$ & $2.81 \pm 3.05$ & $32.08 \pm 19.12$ \\
\hline Propylene & olefin & 26.30 & $3.84 \pm 2.05$ & $0.86 \pm 0.94$ & $7.09 \pm 3.47$ & $5.93 \pm 3.17$ & $1.33 \pm 1.46$ & $10.96 \pm 5.36$ \\
\hline Propane & alkane & 1.15 & $3.61 \pm 1.78$ & $0.70 \pm 0.87$ & $5.08 \pm 1.76$ & $127.59 \pm 62.77$ & $24.64 \pm 30.72$ & $179.58 \pm 62.08$ \\
\hline n-butane & alkane & 2.54 & $3.13 \pm 1.55$ & $0.57 \pm 0.73$ & $4.52 \pm 1.56$ & $50.09 \pm 24.87$ & $9.15 \pm 11.65$ & $72.38 \pm 24.89$ \\
\hline m,p-xylene & aromatic & 18.95 & $2.64 \pm 2.78$ & $0.38 \pm 0.39$ & $5.26 \pm 1.60$ & $5.67 \pm 5.96$ & $0.82 \pm 0.84$ & $11.28 \pm 3.43$ \\
\hline i-butene & olefin & 31.40 & $2.35 \pm 1.40$ & $0.77 \pm 0.87$ & $4.08^{\#}$ & $3.04 \pm 1.81$ & $0.99 \pm 1.13$ & $5.28^{\#}$ \\
\hline 2-methyl-1-butene & olefin & 61.00 & $2.06 \pm 1.96$ & $0.12 \pm 0.09$ & $5.73 \pm 6.32$ & $1.37 \pm 1.30$ & $0.08 \pm 0.06$ & $3.82 \pm 4.21$ \\
\hline Toluene & aromatic & 5.96 & $1.97 \pm 1.37$ & $0.28 \pm 0.28$ & $4.45 \pm 1.04$ & $13.45 \pm 9.33$ & $1.89 \pm 1.92$ & $30.35 \pm 7.07$ \\
\hline 2-methyl-2-butene & olefin & 86.90 & $1.89 \pm 1.25$ & $0.39 \pm 0.52$ & $3.61 \pm 2.08$ & $0.89 \pm 0.58$ & $0.18 \pm 0.24$ & $1.69 \pm 0.97$ \\
\hline t-2-butene & olefin & 64.00 & $1.65 \pm 1.12$ & $0.63 \pm 0.83$ & $3.91 \pm 1.74$ & $1.05 \pm 0.71$ & $0.40 \pm 0.53$ & $2.48 \pm 1.11$ \\
\hline i-pentane & alkane & 3.70 & $1.55 \pm 0.84$ & $0.53 \pm 0.39$ & $2.92 \pm 1.21$ & $17.02 \pm 9.28$ & $5.82 \pm 4.29$ & $32.04 \pm 13.24$ \\
\hline 1,2,4-trimethylbenzene & aromatic & 32.50 & $1.43 \pm 0.80$ & $0.31 \pm 0.26$ & $2.67 \pm 0.87$ & $1.79 \pm 1.00$ & $0.38 \pm 0.33$ & $3.34 \pm 1.09$ \\
\hline $\mathrm{t}$-2-pentene & olefin & 67.00 & $1.22 \pm 0.82$ & $0.33 \pm 0.47$ & $2.25 \pm 1.08$ & $0.74 \pm 0.50$ & $0.20 \pm 0.28$ & $1.36 \pm 0.66$ \\
\hline c-2-butene & olefin & 56.40 & $1.16 \pm 0.67$ & $0.45 \pm 0.65$ & $1.81 \pm 0.82$ & $0.83 \pm 0.49$ & $0.33 \pm 0.47$ & $1.31 \pm 0.59$ \\
\hline i-butane & alkane & 2.19 & $0.99 \pm 0.49$ & $0.21 \pm 0.27$ & $1.47 \pm 0.50$ & $18.37 \pm 9.08$ & $3.98 \pm 5.05$ & $27.36 \pm 9.26$ \\
\hline 1,3-butadiene & olefin & 66.60 & $0.90 \pm 0.66$ & $0.24 \pm 0.28$ & $1.03^{\#}$ & $0.55 \pm 0.40$ & $0.14 \pm 0.17$ & $0.63^{\#}$ \\
\hline Isoprene & olefin & 101.00 & $0.81 \pm 0.68$ & $0.17 \pm 0.11$ & $0.81 \pm 0.47$ & $0.33 \pm 0.27$ & $0.07 \pm 0.04$ & $0.32 \pm 0.19$ \\
\hline 1,3,5-trimethylbenzene & aromatic & 57.50 & $0.80 \pm 0.54$ & $0.20 \pm 0.12$ & $1.60 \pm 0.54$ & $0.57 \pm 0.38$ & $0.14 \pm 0.09$ & $1.13 \pm 0.38$ \\
\hline n-pentane & alkane & 3.94 & $0.72 \pm 0.43$ & $0.11 \pm 0.12$ & $0.91 \pm 0.45$ & $7.41 \pm 4.43$ & $1.14 \pm 1.23$ & $9.44 \pm 4.64$ \\
\hline Hexane & alkane & 5.61 & $0.71 \pm 0.55$ & $0.07 \pm 0.09$ & $1.64 \pm 0.55$ & $5.17 \pm 4.02$ & $0.47 \pm 0.64$ & $11.85 \pm 4.02$ \\
\hline 2-methylpentane & alkane & 5.60 & $0.71 \pm 0.41$ & $0.10 \pm 0.10$ & $1.36 \pm 0.57$ & $5.17 \pm 2.98$ & $0.76 \pm 0.71$ & $9.89 \pm 4.11$ \\
\hline o-xylene & aromatic & 13.70 & $0.70 \pm 0.70$ & $0.10 \pm 0.10$ & $1.37 \pm 0.42$ & $2.08 \pm 2.08$ & $0.29 \pm 0.31$ & $4.07 \pm 1.25$ \\
\hline Styrene & aromatic & 58.00 & $0.66 \pm 0.45$ & $0.57 \pm 0.22$ & $1.34 \pm 0.78$ & $0.46 \pm 0.32$ & $0.40 \pm 0.15$ & $0.94 \pm 0.55$ \\
\hline c-2-pentene & olefin & 65.00 & $0.58 \pm 0.40$ & $0.26 \pm 0.32$ & $1.13 \pm 0.60$ & $0.37 \pm 0.25$ & $0.16 \pm 0.20$ & $0.70 \pm 0.38$ \\
\hline MTBE & oxygenated & 2.90 & $0.50 \pm 0.33$ & $0.05 \pm 0.04$ & $0.97 \pm 0.57$ & $7.04 \pm 4.61$ & $0.64 \pm 0.50$ & $13.53 \pm 8.01$ \\
\hline 3-methylpentane & alkane & 5.70 & $0.47 \pm 0.26$ & $0.07 \pm 0.06$ & $0.95 \pm 0.41$ & $3.33 \pm 1.88$ & $0.48 \pm 0.41$ & $6.76 \pm 2.91$ \\
\hline 3-methylhexane & alkane & 7.20 & $0.46 \pm 0.61$ & $0.09 \pm 0.05$ & $0.50 \pm 0.16$ & $2.61 \pm 3.45$ & $0.53 \pm 0.30$ & $2.81 \pm 0.90$ \\
\hline m-ethyltoluene & aromatic & 19.20 & $0.42 \pm 0.34$ & $0.05 \pm 0.05$ & $0.96 \pm 0.43$ & $0.88 \pm 0.71$ & $0.11 \pm 0.12$ & $2.02 \pm 0.90$ \\
\hline 1-pentene & olefin & 31.40 & $0.37 \pm 0.22$ & $0.18 \pm 0.14$ & $0.91 \pm 0.97$ & $0.48 \pm 0.28$ & $0.23 \pm 0.19$ & $1.18 \pm 1.26$ \\
\hline 2-methylhexane & alkane & 6.80 & $0.33 \pm 0.42$ & $0.06 \pm 0.05$ & $0.39 \pm 0.13$ & $1.98 \pm 2.53$ & $0.38 \pm 0.28$ & $2.34 \pm 0.78$ \\
\hline n-heptane & alkane & 7.15 & $0.33 \pm 0.48$ & $0.03 \pm 0.02$ & $0.39 \pm 0.14$ & $1.85 \pm 2.72$ & $0.16 \pm 0.12$ & $2.23 \pm 0.77$ \\
\hline Methylcyclopentane & alkane & 8.80 & $0.31 \pm 0.17$ & $0.04 \pm 0.03$ & $0.54 \pm 0.20$ & $1.41 \pm 0.77$ & $0.19 \pm 0.13$ & $2.49 \pm 0.94$ \\
\hline Acetylene & alkyne & 0.91 & $0.30 \pm 0.17$ & $0.02 \pm 0.01$ & $0.35 \pm 0.16$ & $13.37 \pm 7.64$ & $0.85 \pm 0.46$ & $15.73 \pm 6.97$ \\
\hline Ethylbenzene & aromatic & 7.10 & $0.28 \pm 0.25$ & $0.05 \pm 0.04$ & $0.55 \pm 0.17$ & $1.62 \pm 1.43$ & $0.26 \pm 0.24$ & $3.12 \pm 0.97$ \\
\hline ethyl acetate & ester & 8.00 & $0.26 \pm 0.21$ & $0.02 \pm 0.01$ & - & $1.35 \pm 1.06$ & $0.11 \pm 0.05$ & - \\
\hline i-octane & alkane & 3.57 & $0.26 \pm 0.15$ & $0.03 \pm 0.02$ & $0.48 \pm 0.22$ & $3.00 \pm 1.68$ & $0.31 \pm 0.20$ & $5.44 \pm 2.55$ \\
\hline p-ethyltoluene & aromatic & 12.10 & $0.23 \pm 0.15$ & $0.07 \pm 0.08$ & $0.32 \pm 0.10$ & $0.78 \pm 0.50$ & $0.23 \pm 0.27$ & $1.08 \pm 0.33$ \\
\hline 2,3,4-trimethylpentane & alkane & 7.00 & $0.22 \pm 0.12$ & $0.01 \pm 0.01$ & $0.31 \pm 0.19$ & $1.26 \pm 0.67$ & $0.08 \pm 0.08$ & $1.78 \pm 1.13$ \\
\hline 2,3-dimethylbutane & alkane & 5.99 & $0.20 \pm 0.22$ & $0.03 \pm 0.02$ & $0.20 \pm 0.28$ & $1.38 \pm 1.52$ & $0.22 \pm 0.16$ & $1.38 \pm 1.91$ \\
\hline 2,3-dimethylpentane & alkane & 7.20 & $0.19 \pm 0.19$ & $0.02 \pm 0.01$ & $0.20 \pm 0.08$ & $1.05 \pm 1.07$ & $0.11 \pm 0.04$ & $1.11 \pm 0.46$ \\
\hline Methylcyclohexane & alkane & 10.40 & $0.16 \pm 0.16$ & $0.04 \pm 0.04$ & $0.23 \pm 0.08$ & $0.62 \pm 0.64$ & $0.15 \pm 0.15$ & $0.89 \pm 0.31$ \\
\hline 2,4-dimethylhexane & alkane & 8.60 & $0.16 \pm 0.09$ & $0.02 \pm 0.02$ & $0.16 \pm 0.06$ & $0.75 \pm 0.43$ & $0.09 \pm 0.08$ & $0.73 \pm 0.31$ \\
\hline 1-hexene & olefin & 37.00 & $0.15 \pm 0.04$ & $0.15^{\#}$ & $0.44^{\#}$ & $0.16 \pm 0.04$ & $0.17^{\#}$ & $0.48^{\#}$ \\
\hline o-ethyltoluene & aromatic & 12.30 & $0.15 \pm 0.08$ & $0.05 \pm 0.04$ & $0.27 \pm 0.08$ & $0.49 \pm 0.26$ & $0.16 \pm 0.15$ & $0.89 \pm 0.26$ \\
\hline Cyclohexane & alkane & 7.49 & $0.14 \pm 0.08$ & $0.03 \pm 0.04$ & $0.23 \pm 0.13$ & $0.77 \pm 0.45$ & $0.19 \pm 0.20$ & $1.27 \pm 0.72$ \\
\hline 2,2-dimethylbutane & alkane & 2.59 & $0.13 \pm 0.09$ & $0.01 \pm 0.01$ & $0.21 \pm 0.13$ & $2.02 \pm 1.38$ & $0.18 \pm 0.12$ & $3.33 \pm 2.08$ \\
\hline n-octane & alkane & 8.70 & $0.12 \pm 0.06$ & $0.03 \pm 0.02$ & $0.25 \pm 0.09$ & $0.58 \pm 0.28$ & $0.14 \pm 0.10$ & $1.16 \pm 0.44$ \\
\hline p-propylbenzene & aromatic & 6.00 & $0.12 \pm 0.07$ & $0.03 \pm 0.03$ & $0.25^{\#}$ & $0.80 \pm 0.44$ & $0.22 \pm 0.20$ & $1.71^{\#}$ \\
\hline n-decane & alkane & 11.20 & $0.12 \pm 0.06$ & $0.04 \pm 0.04$ & $0.23 \pm 0.06$ & $0.42 \pm 0.21$ & $0.15 \pm 0.15$ & $0.85 \pm 0.23$ \\
\hline Ethane & alkane & 0.27 & $0.11 \pm 0.08$ & $0.02 \pm 0.02$ & $0.28 \pm 0.11$ & $17.26 \pm 11.62$ & $3.05 \pm 3.74$ & $41.78 \pm 16.04$ \\
\hline Nonane & alkane & 10.00 & $0.11 \pm 0.06$ & $0.02 \pm 0.02$ & $0.24 \pm 0.06$ & $0.45 \pm 0.24$ & $0.08 \pm 0.08$ & $1.00 \pm 0.23$ \\
\hline Benzene & aromatic & 1.23 & $0.10 \pm 0.05$ & $0.02 \pm 0.03$ & $0.18 \pm 0.07$ & $3.17 \pm 1.75$ & $0.80 \pm 0.91$ & $6.07 \pm 2.15$ \\
\hline 2,5-dimethylhexane & alkane & 8.30 & $0.07 \pm 0.06$ & $0.11 \pm 0.21$ & - & $0.36 \pm 0.29$ & $0.52 \pm 1.04$ & - \\
\hline 2-methylheptane & alkane & 8.20 & $0.07 \pm 0.04$ & $0.02 \pm 0.01$ & $0.16^{\#}$ & $0.36 \pm 0.21$ & $0.10 \pm 0.07$ & $0.77^{\#}$ \\
\hline Propyne & alkyne & 5.90 & $0.07 \pm 0.03$ & $0.04^{\#}$ & $0.15^{\#}$ & $0.49 \pm 0.21$ & $0.25^{\#}$ & $1.04^{\#}$ \\
\hline n-propylbenzene & aromatic & 6.00 & $0.07 \pm 0.03$ & $0.01 \pm 0.01$ & $0.11 \pm 0.04$ & $0.46 \pm 0.23$ & $0.08 \pm 0.06$ & $0.77 \pm 0.24$ \\
\hline Cyclopentane & alkane & 5.02 & $0.05 \pm 0.04$ & $0.01 \pm 0.01$ & $0.02 \pm 0.01$ & $0.38 \pm 0.35$ & $0.07 \pm 0.06$ & $0.13 \pm 0.11$ \\
\hline $1,2,4$ trimethyl cyclohexane & alkane & 7.50 & $0.04 \pm 0.02$ & $0.01 \pm 0.00$ & $0.08^{\#}$ & $0.20 \pm 0.10$ & $0.04 \pm 0.03$ & $0.42^{\#}$ \\
\hline
\end{tabular}

* OH reaction rate coefficients at $298 \mathrm{~K}$ and $1 \mathrm{~atm}\left(\mathrm{~cm}^{3}\right.$ molecule $\left.{ }^{-1} \mathrm{~s}^{-1}\right) \times 10^{-12}$, (Atkinson, 1994, 1997).

$\S$ Products of mean individual VOC concentrations and $\mathrm{OH}$ reaction rate coefficients. To obtain the $\mathrm{OH}$ reactivity in units of $\mathrm{s}^{-1}$ the VOC ambient concentrations were transformed to units of molecule $\mathrm{cm}^{-3}$.

\# There was only one available data. 
bient concentrations during the morning rush hour. Average reactivity levels and concentrations are shown in columns according to the site type: urban, rural (Santa Ana Tlacontenco, La Reforma and Teotihuacan) and industrial (Xalostoc). For the urban sites, the reactivity values were calculated independently for each monitored site but, as the results were quite similar, only the reactivity values calculated for the average concentrations are presented. VOCs are sorted in descending order according to their reactivity in urban sites. It is important to point out that many oxygenated VOCs and carbonyls were not considered in this analysis, and therefore it is more appropriate to use the term non methane hydrocarbons (NMHC) instead of VOCs. The $\mathrm{OH}$ reaction rate coefficients shown in Table 4 correspond to the coefficients published by Atkinson $(1994,1997)$ at $298 \mathrm{~K}$ and $1 \mathrm{~atm}$. Where no information was available, the $\mathrm{OH}$ reaction rate coefficient was estimated from information on similar compounds.

The ten most important NMHC in the urban atmosphere of the Valley of Mexico in terms of $\mathrm{OH}$ reactivity include two aromatics, six olefins and two alkanes: ethylene, propylene, propane, n-butane, m,p-xylenes, i-butene, 2-methyl-1butene, toluene, 2-methyl-2-butene and t-2-butene. It is important to point out that the two most reactive NMHC at urban sites were also the top two NMHC reported for the industrial site. These species are olefins mainly emitted by vehicles with high concentrations and high reaction rate coefficients. Also, it is important to highlight that the elevated concentrations of propane and n-butane are sufficient to rank these two alkanes among the top 5 NMHC, even though their reactivity rate coefficients are small compared to those for olefins and aromatics. Using a Total $\mathrm{OH}$ Loss Measurement instrument (TOHLM) Shirley et al. (2006) measured an $\mathrm{OH}$ reactivity of $\sim 120 \mathrm{~s}^{-1}$ during the morning rush hours at the CENICA site and estimated that $72 \%$ of it was due to VOCs.

Overall, major NMHC in terms of ozone production in the Valley of Mexico are of anthropogenic origin. Biogenic NMHC seem to be relatively insignificant. Isoprene concentrations were low $(0.33 \pm 0.27 \mathrm{ppbv}$ in urban sites) compared to other reactive species, and were assumed to have their origin more from vehicle exhaust than from vegetation. Different studies have reveled that the isoprene has a strong anthropogenic origin (Borbon et al., 2001), particularly in urban areas with scarce vegetation. The olefin fluxes measured at the urban site of CENICA did not show the typical biogenic peak of isoprene around noon when solar radiation and temperature are highest (Velasco et al., 2005). With the knowledge that 1,3-butadiene is a good tracer for vehicle exhaust (Ye et al., 1997), we compared the morning ambient concentrations of isoprene and 1,3-butadiene measured at the urban sites. The regression between these two species was nearly linear; although it showed some dispersion, it suggests that both species share the same emission sources. Using the onroad samples collected by the Aerodyne mobile-laboratory, which are described in detail in Sect. 5.4, we found an isoprene to 1,3 -butadiene ratio of 0.27 , comparable to the ra- tio of 0.30 obtained for the ambient samples at the urban sites. These ratios are similar to those reported for other urban and suburban sites (Borbon et al., 2001; Reinmann et al., 2000). Vegetation was sparse at the three monitored rural sites, and, therefore, isoprene concentrations were also low $(0.07 \pm 0.04 \mathrm{ppbv})$. At rural sites, low molecular weight alkanes were the most abundant species, emitted from LPG leakages as it has been discussed before. At rural sites, one of the most reactive hydrocarbons was styrene, with ambient concentrations similar to those observed at urban sites $(0.57 \pm 0.22 \mathrm{ppbv})$. The presence of styrene in these rural environments is attributed to local biomass and trash burning.

A comparison of the reactivity levels between the urban sites and industrial site indicates that on average the air in the industrial location is 1.8 times more reactive than at the urban sites. Half of the measured VOCs at the industrial site had reactivity levels between 1.4 and 2.1 times higher than at the urban sites. A similar comparison between urban and rural sites shows that the urban atmosphere is 4.6 times more reactive than the rural atmosphere in the Valley of Mexico.

\subsection{Distribution of VOCs by compound type}

Figure 6 shows the VOC distributions by compound type during the morning (6:00 to 9:00 h) and afternoon (12:00 to $15: 00 \mathrm{~h}$ ) from canister samples collected and analyzed by the WSU and IMP groups. Note that concentrations are in ppbC. Hereafter all contribution fractions are based on $\mathrm{ppbC}$, as well. In the morning, the entire valley experiences a relatively homogeneous mix of VOCs consisting of $\sim 60 \%$ alkanes, $\sim 15 \%$ aromatics, $\sim 5 \%$ olefins and a remaining $20 \%$ of alkynes, halogenated hydrocarbons, oxygenated species (esters, ethers, carbonyls, etc.) and other unidentified VOCs. In our study, concentrations of total VOCs in the industrial area were 1.6 times higher than at urban sites during the morning period, while concentrations at rural sites were about one-sixth of those measured at the urban locations. In the afternoon, VOC concentrations were less and the distribution among species was different with a higher contribution of unidentified VOCs at the urban sites. The reduction in concentrations from morning to afternoon were: alkanes $70 \%$, olefins $60 \%$, aromatics $53 \%$, and unidentified VOCs $20 \%$. Lower afternoon concentrations are normally ascribed to increased dispersion and photochemical oxidation during the midday period. However, employing these mechanisms alone is insufficient to explain those reductions, because the relatively unreactive alkanes showed the largest proportional loss. Emission rates must be a factor, as well, with a large decrease in alkane emissions relative to aromatics and olefins. A reduction in the emission rate of alkanes from morning to afternoon could be due to reduced consumption of LPG (propane, i-butane, n-butane) during the afternoon hours. LPG is used by Mexican household to heat water for bathing and showering prior to going to work in the morning. Leakage from LPG transmission systems will be 
largest during the morning period of maximum usage. Santa Ana Tlacotenco, a rural downwind boundary site, showed an opposite pattern. Relatively low local emissions coupled with transport emissions from the urban region resulted in afternoon VOC concentrations 2.4 higher than in the morning.

Hydrocarbons. At urban and industrial sites during the morning period, hydrocarbons with four or less carbons represent the major fraction of the alkanes and alkenes. The main contributors are propane, n-butane, ethylene, propylene, and the sum of $\mathrm{i}-\mathrm{t} \mathrm{t}-2-$ and $-\mathrm{c}-2$ butenes. 1,3-butadiene is a four-carbon diene that is considered to be a carcinogenic and reproductive toxicant to humans, whose main source is vehicle exhaust (USEPA, 1999b). 1,3-butadiene is of concern in Mexico City because of its relatively elevated concentrations: 0.55 and 0.63 ppbv at urban and industrial sites, respectively.

The most abundant aromatics were the BTEX species (benzene, toluene ethylbenzene and the xylene isomers). They accounted for about $75 \%$ of the aromatic burden. The average toluene concentration was $13.45 \pm 9.33 \mathrm{ppbv}$ at urban sites and $30.35 \pm 7.07 \mathrm{ppbv}$ at the industrial area. Total xylene concentrations averaged $15.35 \pm 4.68 \mathrm{ppbv}$ at the industrial site and about half of that (7.75 18.14$)$ in the urban area. Ethylbenzene had average concentrations about the same as the individual xylene isomers with concentrations of $1.62 \pm 1.43 \mathrm{ppbv}$ in the urban areas and about $3.12 \pm 0.97 \mathrm{ppbv}$ in the industrial region. Benzene averaged $6.07 \pm 2.15$ and $3.17 \pm 1.75 \mathrm{ppbv}$ at the industrial and urban sites, respectively. The urban benzene concentration determined in this study is similar to that reported by Bravo et al. (2002) for residential areas in southwest Mexico City.

Oxygenated hydrocarbons. MTBE is the only oxygenated VOC listed in Table 4. MTBE is used as an additive in unleaded gasoline to enhance the combustion efficiency. In our canister samples, MTBE contributes no more than $2 \%$ to the total VOC burden of the Valley of Mexico. Ethyl tertiary butyl ether (ETBE) was another oxygenated VOC identified in the samples analyzed by IMP. ETBE is not included in Table 4 because it was measured at only half of the sites (Xalostoc, Pedregal, CENICA and La Merced). Average ETBE concentrations were 0.3 and $0.6 \mathrm{ppbv}$ at urban and industrial sites, respectively, $96 \%$ lower than the average MTBE concentrations at both types of site. Both MTBE and ETBE have their origin from vehicle exhaust due to incomplete combustion and gasoline evaporation from fueling stations and vehicle gasoline tanks.

During the MCMA-2003 study, ambient concentrations of formaldehyde were measured by DOAS at two different sites: CENICA and La Merced. The monthly average concentrations at CENICA and La Merced were 8.2 \pm 4.6 and $6.0 \pm 4.7$ ppbv, respectively (Volkamer et al., 2005; Grutter et al., 2005). Garcia et al. (2005) determined on a $24 \mathrm{~h}$ average basis, that mobile and industrial sources contribute $42 \%$ to the ambient concentration of formaldehyde, the atmospheric oxidation of numerous VOCs contribute greater than $38 \%$
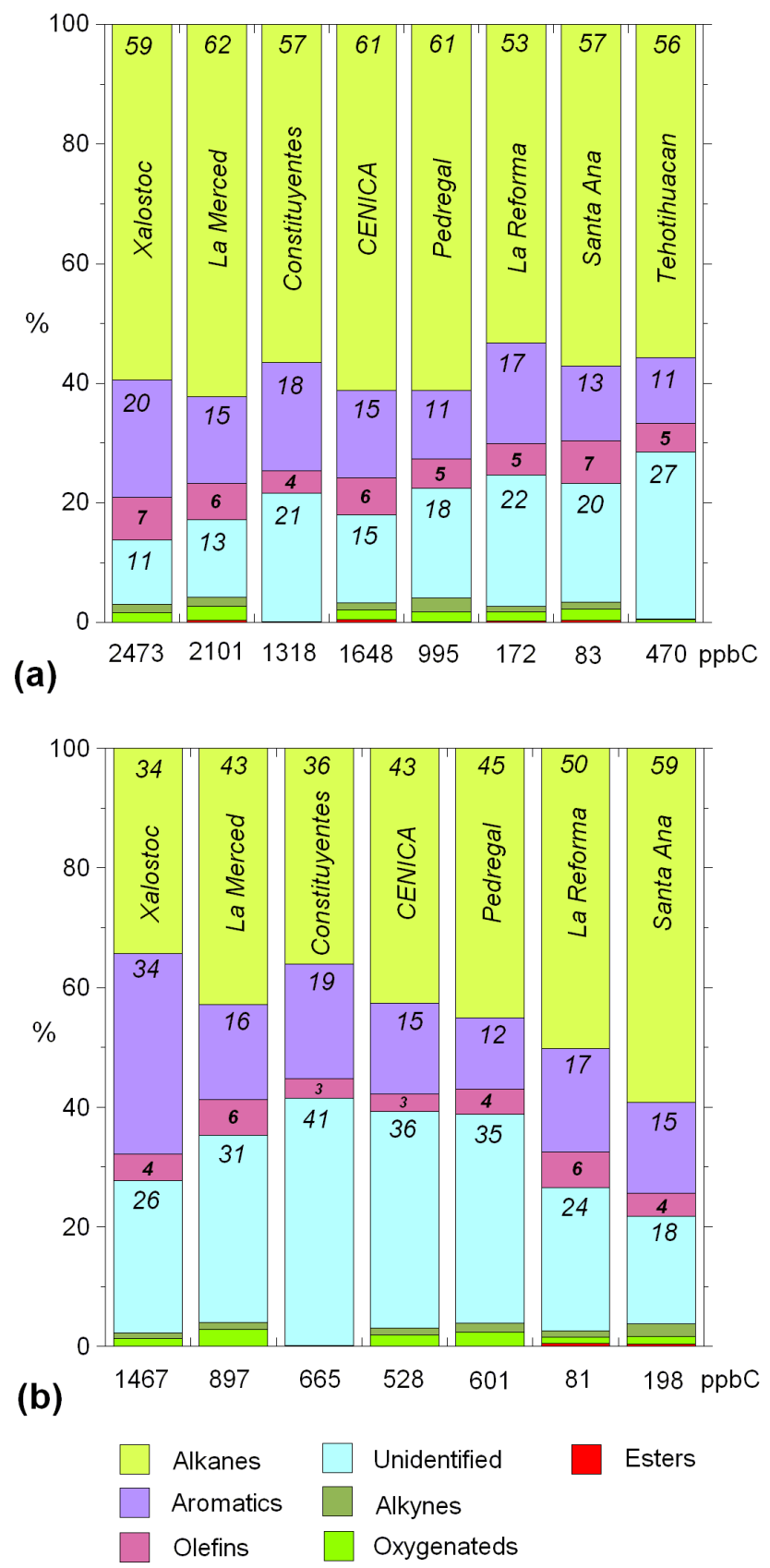

Fig. 6. VOC distribution by compound type during the morning (a) and afternoon (b). Numbers in the columns indicate the percent contribution of each VOC group to the total VOC concentration, which is displayed at the bottom of each column in ppbC.

and the remaining $20 \%$ is due mainly to uncounted industrial processes.

Glyoxal was another oxygenated hydrocarbon detected directly by DOAS at the CENICA site in 2003. Volkamer et al. (2005) found that glyoxal is predominantly formed from 
Table 5. Ambient average concentrations of halogenated VOCs measured during the MCMA-2003 study at urban (Pedregal, La Merced and CENICA) and industrial (Xalostoc) sites of the Valley of Mexico. The numbers at the right of the \pm symbol indicate one standard deviation. Concentrations below the detection limit are indicate as $<$ DL.

\begin{tabular}{lcccc}
\hline Species & \multicolumn{2}{c}{ Urban sites (ppbC) } & \multicolumn{2}{c}{ Industrial site (ppbC) } \\
& $6-9 \mathrm{~h}$ & $12-15 \mathrm{~h}$ & $6-9 \mathrm{~h}$ & $12-15 \mathrm{~h}$ \\
\hline p-dichlorobenzene & $5 \pm 4$ & $2 \pm 1$ & $6 \pm 2$ & $3 \pm 1$ \\
Trichloroethylene & $4 \pm 3$ & $2 \pm 1$ & $4 \pm 2$ & $1 \pm 0$ \\
1,2 -dichloropropane & $4 \pm 2$ & $3 \pm 1$ & $0 \pm 0$ & $<\mathrm{DL}$ \\
1,2 -dichloroethane & $3 \pm 3$ & $2 \pm 2$ & $1 \pm 1$ & $<\mathrm{DL}$ \\
c-1,3-dichlopropene & $3 \pm 3$ & $2 \pm 1$ & $6 \pm 3$ & $4 \pm 2$ \\
o-dichlorobenzene & $3 \pm 2$ & $0 \pm 0$ & $5 \pm 1$ & $<\mathrm{DL}$ \\
1,1 -dichloroethane & $2 \pm 2$ & $2 \pm 2$ & $1 \pm 2$ & $2 \pm 2$ \\
Chloroform & $1 \pm 1$ & $<\mathrm{DL}$ & $3 \pm 2$ & $1 \pm 0$ \\
t-1,3-dichloropropene & $1 \pm 1$ & $<\mathrm{DL}$ & $1 \pm 1$ & $<\mathrm{DL}$ \\
Freon113 & $1 \pm 1$ & $1 \pm 1$ & $1 \pm 1$ & $<\mathrm{DL}$ \\
perchloroethylene & $1 \pm 1$ & $<\mathrm{DL}$ & $1 \pm 1$ & $<\mathrm{DL}$ \\
Chlorobenznene & $<\mathrm{DL}$ & $<\mathrm{DL}$ & $<\mathrm{DL}$ & $1 \pm 1$ \\
Vinyl chloride & $<\mathrm{DL}$ & $<\mathrm{DL}$ & $<\mathrm{DL}$ & $1 \pm 1$ \\
m-dichlorobenzene & $<\mathrm{DL}$ & $1 \pm 1$ & $<\mathrm{DL}$ & $<\mathrm{DL}$ \\
Subtotal Halogenates & $28 \pm 23$ & $15 \pm 10$ & $29 \pm 16$ & $13 \pm 7$ \\
Halogens percent between unidentified VOCs* & $21.6 \pm 9.1$ & $20.0 \pm 8.8$ & $24.0 \pm 3.9$ & $22.4 \pm 4.6$ \\
Halogens percent between total VOCs* & $1.4 \pm 0.5$ & $1.8 \pm 0.7$ & $1.1 \pm 0.2$ & $1.2 \pm 0.3$ \\
\hline
\end{tabular}

* These average percents were calculated with the samples in which halogenated VOCs were analyzed.

airborne VOC oxidation in the atmosphere of Mexico City, reaching peaks around $1.8 \mathrm{ppbv}$ between 10 and 13:00 h. The ambient concentrations of glyoxal were about one order of magnitude less affected by vehicle emissions than those of formaldehyde, and thus present a well suitable indicator molecule for VOC oxidation processes.

Halogenated hydrocarbons. The GC-FID technique can be used to identify halogenated VOCs, but not to precisely quantify their concentration, since halogenated VOCs contain other atoms besides carbon and hydrogen. However, IMP quantified 14 halogenated VOCs at the Xalostoc, Pedregal, CENICA and La Merced sites. Table 5 shows that the set of identified halogenated species contributes less than $2 \%$ to the total VOC burden. All of them are emitted by anthropogenic sources. Many of them are classified as toxic and carcinogenic species, and others, such as the vinyl chloride, are suspected to cause congenital malformation (IPCS, 2005). Another concern is the very long atmospheric residence times of some halogenated VOCs, in particular chlorofluorocarbons such as Freon 113. They can eventually diffuse into the stratosphere where photolysis produces chlorine radicals, which catalytically destroy ozone and indirectly contribute to the greenhouse effect. Even though the use of chlorofluorocarbons as refrigerants is not allowed anymore, chlorofluorocarbon emissions occur during the disposal of old refrigeration units and, in developing cities such as Mexico City, leakage from old residential refrigerators may also be a significant source.
5.4 Comparison of ambient VOC concentrations to vehicles exhaust signatures

Since roadway vehicle emissions are normally the dominant VOC source in urban areas (Watson et al., 2001), it was of interest to compare the mixing ratios obtained from canister sampling at the urban sites to the vehicle exhaust source signature measured during mobile vehicle chase experiments.

Briefly, vehicle chase measurements were made using the Aerodyne mobile laboratory equipped with several instruments to characterize emissions from vehicles under actual driving conditions (see Herndon et al., 2005; Herndon et al., 2007²; Zavala et al., 2006; Rogers et al., 2007). In chase mode, the Aerodyne van was driven immediately behind a selected vehicle for approximately 5 to $20 \mathrm{~min}$. Vehicle plume samples were collected with an auto-sampling system that included a fast response $\mathrm{CO}_{2}$ sensor (LICOR LI7000). Distinct peaks in the $\mathrm{CO}_{2}$ mixing ratio during a vehicle chase indicated interception of the exhaust plume. When the $\mathrm{CO}_{2}$ levels were elevated above a selected threshold, a conditional VOC sampler was manually activated to sample into a "chase" canister and when $\mathrm{CO}_{2}$ levels were below the threshold, air was channeled into an "on-road background" canister (Herndon et al., 2005, 2007²).

\footnotetext{
${ }^{2}$ Herndon, S. C., Kolb, C. E., Lamb, B., Westberg, H., Allwine, E., Velasco, E., Knighton, B., Zavala, M., Molina, L. T. and Molina, J. M.: Conditional sampling of volatile organic compounds in onroad vehicle plumes, in preparation, 2007.)
} 
Table 6. Hydrocarbon molar ratios ( $\mathrm{ppbC} / \mathrm{ppbC}$ ) measured at the industrial, urban and rural sites and from vehicle chase operation during the MCMA-2002 and 2003 field studies. Also ratios from vehicles exhaust studies in North America are shown for comparison.

\begin{tabular}{|c|c|c|c|c|c|c|c|c|c|c|c|}
\hline & \multicolumn{2}{|c|}{ Industrial } & \multicolumn{2}{|c|}{ Urban } & \multicolumn{2}{|c|}{ Rural } & \multicolumn{2}{|c|}{ Vehicular chases } & \multirow{2}{*}{$\begin{array}{c}\begin{array}{c}\text { Mexican gasoline } \\
\text { vehicles }\end{array} \\
\text { Average }\end{array}$} & \multirow{2}{*}{$\begin{array}{c}\begin{array}{c}\text { Mexican diesel } \\
\text { vehicles }\end{array} \\
\text { Average }\end{array}$} & \multirow{2}{*}{$\begin{array}{c}\begin{array}{c}\text { US \& Canada ligh } \\
\text { duty vehicles }\end{array} \\
\text { Average }^{@}\end{array}$} \\
\hline & G. Mean* & Median & G. mean* & Median & G. mean* & Median & G. mean* & Median & & & \\
\hline \multicolumn{12}{|c|}{ Alkene ratios } \\
\hline t-2-butene/c-2-butene & $1.53 \pm 0.91$ & 1.25 & $1.28 \pm 0.83$ & 1.21 & $1.52 \pm 0.66$ & 1.48 & $1.11 \pm 0.50$ & 1.10 & 1.17 & 1.00 & $1.27 \pm 0.33$ \\
\hline $\mathrm{t}$-2-pentene/c-2-pentene & $1.71 \pm 0.51$ & 1.91 & $1.97 \pm 0.53$ & 2.07 & $1.75 \pm 0.51$ & 1.89 & $1.93 \pm 0.46$ & 1.98 & - & 9.33 & $1.78 \pm 0.19$ \\
\hline 1-hexene/1-pentene & $0.46 \pm 0.46$ & 0.52 & $0.52 \pm 0.48$ & 0.59 & - & - & - & - & - & - & $0.49 \pm 0.25$ \\
\hline 1,3-butadiene/t-2-pentene & $0.98 \pm 0.58$ & 1.14 & $0.78 \pm 0.52$ & 0.77 & $0.56 \pm 0.47$ & 0.64 & $0.87 \pm 0.97$ & 0.96 & - & - & $1.36 \pm 0.51$ \\
\hline propylene/ethylene & $0.45 \pm 0.30$ & 0.44 & $0.50 \pm 0.68$ & 0.42 & $0.38 \pm 0.28$ & 0.44 & $0.51 \pm 0.37$ & 0.50 & 0.55 & 0.71 & $0.30 \pm 0.04$ \\
\hline \multicolumn{12}{|c|}{ Alkane ratios } \\
\hline i-butane/n-butane & $0.38 \pm 0.04$ & 0.37 & $0.37 \pm 0.03$ & 0.37 & $0.40 \pm 0.07$ & 0.41 & $0.36 \pm 0.04$ & 0.36 & 0.32 & 0.48 & $0.19 \pm 0.08$ \\
\hline i-pentane/n-pentane & $3.58 \pm 0.69$ & 3.62 & $2.80 \pm 1.41$ & 2.59 & $6.96 \pm 6.61$ & 8.08 & $2.57 \pm 1.69$ & 2.36 & 2.63 & 4.27 & $2.97 \pm 0.57$ \\
\hline $\begin{array}{l}\text { 2-methylpentane/ } \\
\text { 3-methylpentane }\end{array}$ & $1.36 \pm 0.19$ & 1.41 & $1.51 \pm 1.80$ & 1.54 & $1.57 \pm 0.78$ & 1.59 & $1.48 \pm 0.14$ & 1.47 & 1.67 & 1.18 & $1.69 \pm 0.11$ \\
\hline Hexane/2-methylpentane & $1.11 \pm 0.31$ & 1.11 & $0.71 \pm 0.40$ & 0.72 & $0.67 \pm 0.83$ & 0.69 & $0.62 \pm 0.15$ & 0.65 & 0.78 & 1.02 & $0.52 \pm 0.05$ \\
\hline Cyclohexane/n-heptane & $0.78 \pm 1.03$ & 0.50 & $0.56 \pm 0.60$ & 0.50 & $0.76 \pm 0.74$ & 0.91 & $0.61 \pm 0.63$ & 0.54 & 0.86 & 0.29 & $0.43 \pm 0.17$ \\
\hline n-octane/nonane & $0.76 \pm 0.38$ & 1.01 & $1.39 \pm 0.82$ & 1.29 & $1.14 \pm 0.62$ & 1.12 & $1.30 \pm 0.43$ & 1.28 & 1.04 & 0.55 & $1.49 \pm 0.05$ \\
\hline \multicolumn{12}{|c|}{ Aromatic ratios } \\
\hline Toluene/benzene & $8.10 \pm 4.57$ & 8.81 & $5.06 \pm 2.32$ & 4.89 & $3.53 \pm 1.35$ & 3.45 & $3.96 \pm 1.34$ & 3.80 & 2.78 & 5.05 & $1.59 \pm 0.28$ \\
\hline ethylbenzene/toluene & $0.08 \pm 0.04$ & 0.09 & $0.12 \pm 0.05$ & 0.13 & $0.15 \pm 0.07$ & 0.15 & $0.14 \pm 0.05$ & 0.15 & 0.21 & 0.30 & $0.17 \pm 0.03$ \\
\hline isopropylbenzene/toluene & $0.010 \pm 0.005$ & 0.01 & $0.010 \pm 0.008$ & 0.020 & - & - & - & - & 0.027 & 0.016 & $0.020 \pm 0.008$ \\
\hline o-xylene/m,p-xylene & $0.36 \pm 0.03$ & 0.36 & $0.40 \pm 0.07$ & 0.39 & $0.38 \pm 0.11$ & 0.40 & $0.39 \pm 0.05$ & 0.39 & 0.39 & 0.36 & $0.38 \pm 0.02$ \\
\hline $\begin{array}{l}\text { Styrene/ } \\
1,3,5 \text {-trimethylbenzene }\end{array}$ & $0.88 \pm 0.68$ & 0.98 & $1.16 \pm 1.67$ & 1.22 & $3.45 \pm 3.58$ & 3.10 & $0.57 \pm 0.42$ & 0.55 & 0.37 & 0.84 & $0.81 \pm 0.21$ \\
\hline $\begin{array}{l}\text { 1,2,3-trimethylbenzene/ } \\
\text { 1,2,4-trimethylbenzene }\end{array}$ & $0.38 \pm 0.09$ & 0.36 & $0.40 \pm 0.13$ & 0.37 & - & - & - & - & - & - & $0.25 \pm 0.07$ \\
\hline
\end{tabular}

* Geometric mean \pm 1 standard deviation.

$\S$ From vehicle emission profiles measured in Mexico City in 1998 (Mugica et al., 2001b).

\# Average vehicle exhaust ratio calculated by Jobson et al. (2004) from six tunnel studies conducted in the 1990s (Conner et al., 1995; Kirchstetter et al., 1996; Sagebiel et al., 1996; Fraser et al., 1998; Rogak et al., 1998).

@ Average \pm 1 standard deviation.

For the comparison between ambient and vehicular emission data, it is necessary to remove the impact of photochemical aging on source signatures. This is achieved by regressions between species with similar atmospheric lifetimes. The source ratio is preserved for species with similar lifetimes because photochemical loss and mixing will result in similar rates of concentration change (Parrish et al., 1998). This procedure allowed all of the ambient data to be used, including afternoon data when mixing ratios were typically lower due to mixing and photochemical removal. The slope obtained in ambient data plots defines the source ratio that can be directly compared to the vehicular chase measurements and literature values. In practice, there are a limited number of species that can be employed in this analysis because photochemical loss rates must be similar. We have generally constrained the hydrocarbon pairings such that $\mathrm{OH}$ rate coefficients differ by $20 \%$ or less. The exception is the regression between propylene and ethylene where rate constants differ by a factor of three.

Correlations between selected alkenes, alkanes and aromatics are shown in Figs. 7, 8 and 9, respectively. The geometric mean ratios from the vehicular chase data and from the ambient sampling at urban, rural and industrial sites are tabulated in Table 6. In addition, Table 6 shows average exhaust ratios for Mexican gasoline and diesel vehicles from a tunnel study conducted in Mexico City (Mugica et al., 2001b). An average vehicle exhaust ratio for light duty vehicles calculated by Jobson et al. (2004) from six published tunnel studies conducted in the 1990s in US and Canada is included in the table, as well.

In the alkene group, t-2-pentene versus c-2-pentene exhibits excellent agreement between the ambient and vehicular emission ratios. The ambient concentrations span three orders of magnitude due to atmospheric processing and variations in source strength. In general, the highest concentrations were recorded during vehicular chase experiments. In a few cases, ambient industrial and urban samples approached vehicle chase concentrations. The very good agreement between the exhaust emission and ambient ratios for the 2pentenes clearly implies a vehicle exhaust source signature. The t-2-butene versus the c-2-butene correlation shows reasonable agreement between vehicular chase emissions, ambient ratios and literature values. The similarity of the ambient and vehicle exhaust ratios for these species suggests vehicle exhaust as their primary source. For 1-hexene and 1pentene, ambient data showed considerable scatter suggest- 

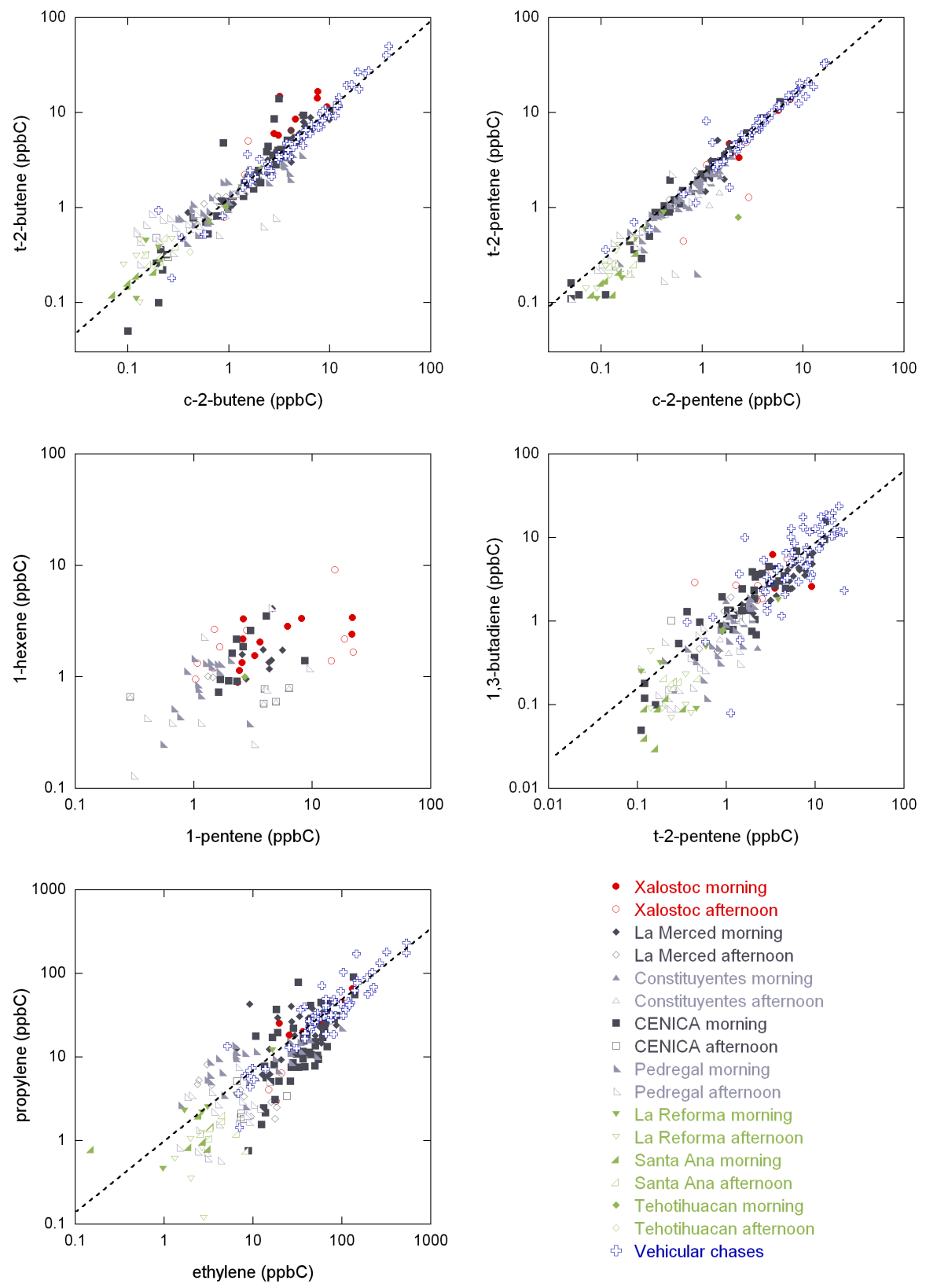

Fig. 7. Correlations between alkenes comparing ambient data to vehicle chase samples. Ambient data correspond to all canister samples and the dashed line indicates the regression line for vehicular chase data.

ing that each site is impacted by a mix of different sources, and that sources and emission rates of 1-hexene are not strongly correlated with sources and emission rates of 1pentene. The propylene:ethylene ratio displays a fair correlation but contains considerable scatter. The vehicle emission ratio $(0.51 \pm 0.37)$ bisects the ambient data, but the large amount of scatter about this ratio is indicative of multiple independent sources. The exhaust emissions ratio itself has a high degree of scatter, suggesting that the emission relation of these species may vary considerably within the Mexican fleet. As indicated previously, propylene and ethylene rate constants vary much more than for the other alkene pairs, which may contribute also to the poor correlations observed for these species.

Ratios for i-butane:n-butane showed excellent agreement between the ambient, vehicular emission and literature values. Note that the average ratios in Table 6 for ambient $(0.38$ industrial and 0.37 urban) and vehicle exhaust (0.36) are essentially equal. Mugica et al. (2001b) reported exhaust emission ratios of 0.32 and 0.48 for gasoline and diesel vehicles in 

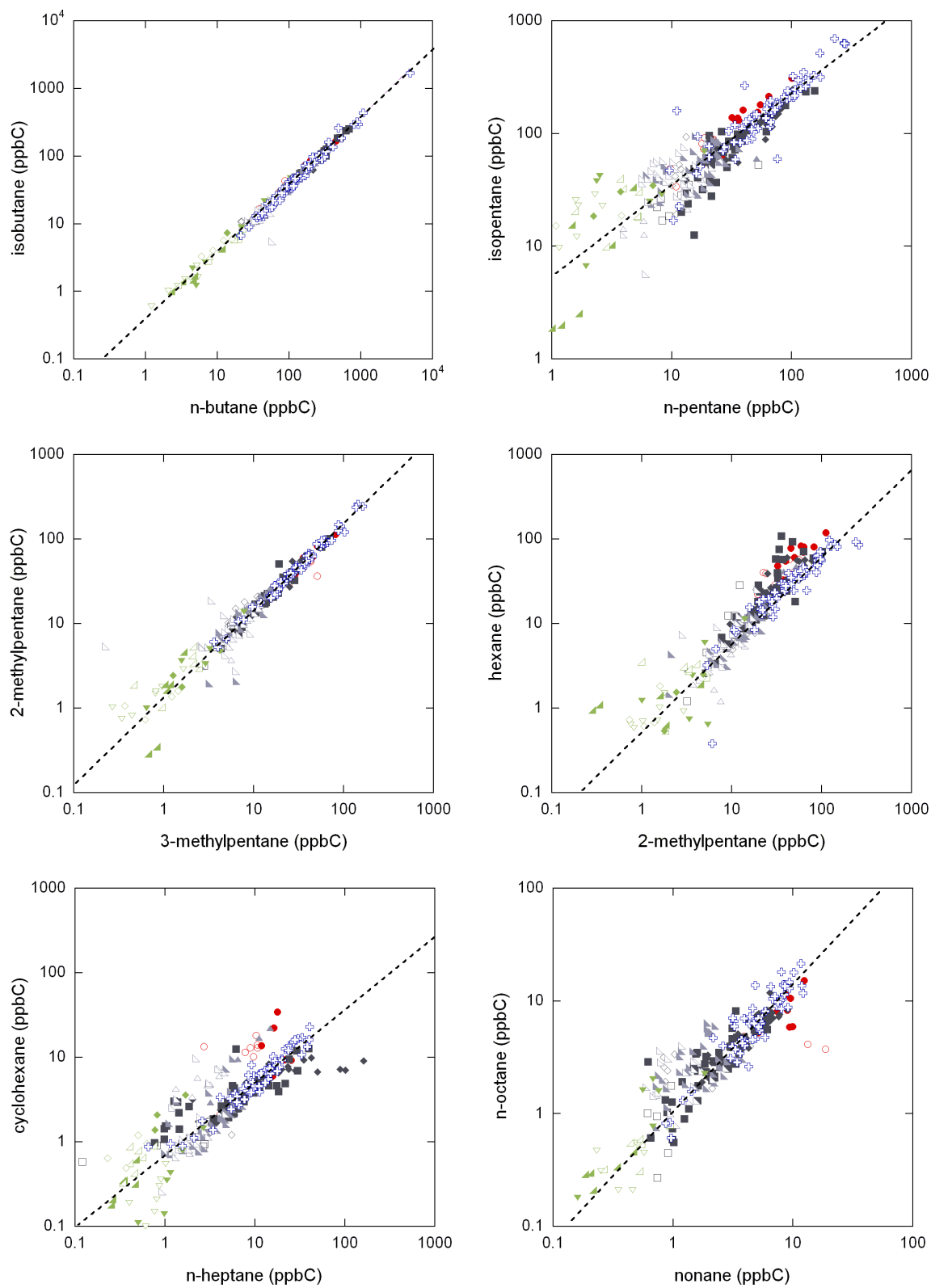

- Xalostoc morning
Xalostoc afternoon
- La Merced morning
La Merced afternoon
$\Delta$ Constituyentes morning
$\Delta$ Constituyentes afternoon

- CENICA morning

- CENICA afternoon

- Pedregal morning

Pedregal afternoon

- La Reforma morning

La Reforma afternoon

4 Santa Ana morning

Santa Ana afternoon

- Tehotihuacan morning

Tehotihuacan afternoor

Vehicular chases

Fig. 8. Correlations between alkanes comparing ambient data to vehicle chase samples. Ambient data correspond to all canister samples and the dashed line indicates the regression line for vehicular chase data.

Mexico. These results suggest that vehicle exhaust is also an important source of $n$-butane and i-butane in addition to LPG leakage. Mugica et al. (2002b) through a source apportionment analysis determined that vehicle exhaust contributes $20 \%$ to the emission of these two alkanes, while handling and distribution of LPG releases $\sim 65 \%$. Although LPG powered vehicles represent less than $1 \%$ of the total fleet, they should also be considered important sources. Schifter et al. (2000) evaluated the LPG vehicles program implemented in Mexico City and found that $95 \%$ of them have emissions that exceed 

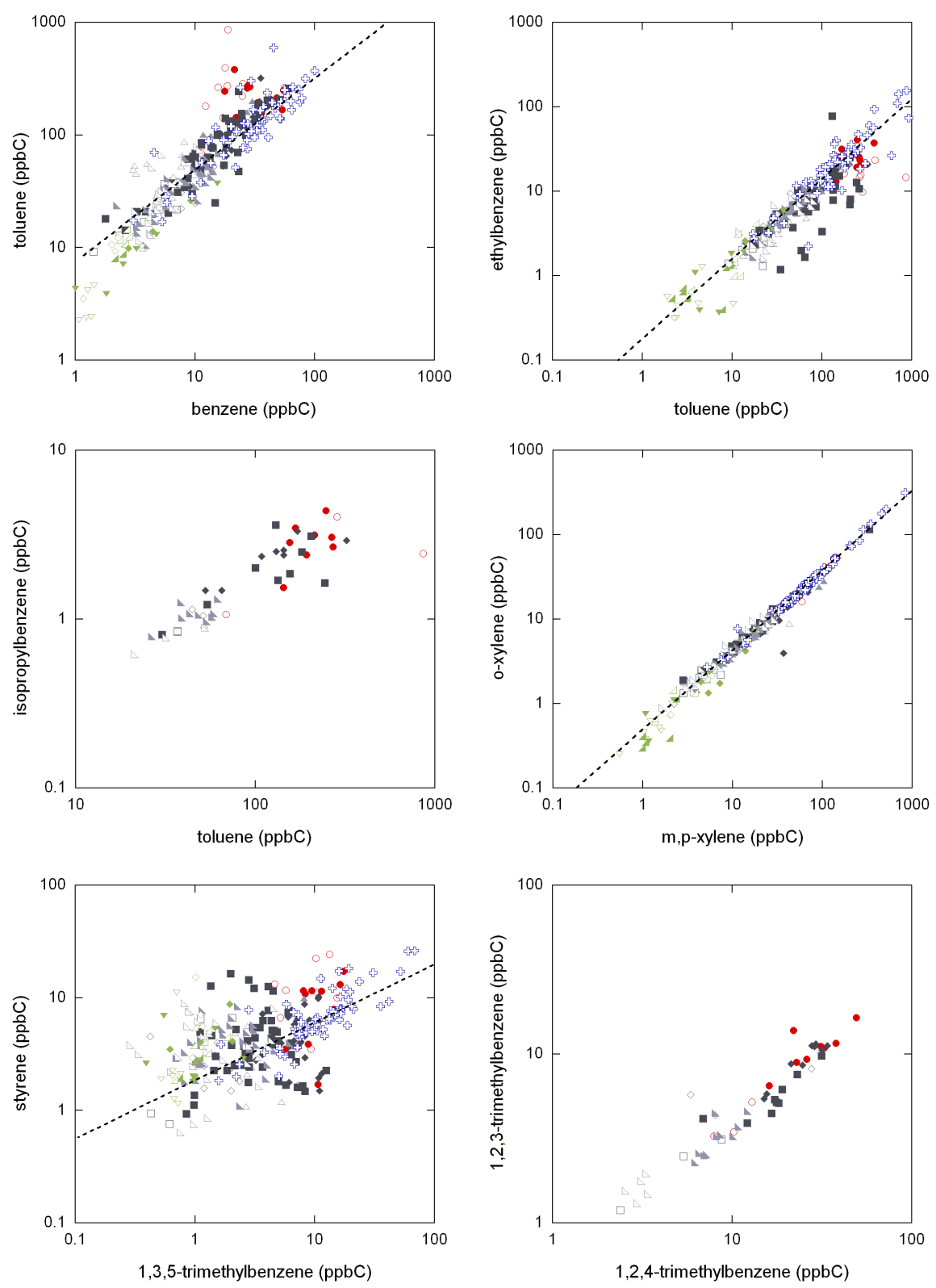

- Xalostoc morning

Xalostoc afternoon

- CENICA morning CENICA afternoon

4 Santa Ana morning Santa Ana afternoon

- La Merced morning La Merced afternoon

- Pedregal morning

Tehotihuacan morning

Tehotihuacan afternoor

- Constituyentes morning

- Pedregal afternoon

- La Reforma morning

Constituyentes afternoon

La Reforma afternoon

Vehicular chases

Fig. 9. Correlations between aromatics comparing ambient data to vehicle chase samples. Ambient data correspond to all canister samples and the dashed line indicates the regression line for vehicular chase data.

those required by environmental regulations. The LPG fleet is composed mainly of vehicles used intensively (light and heavy duty trucks, and small buses with 20-passenger capacity). Gasca et al. (2004) reported that tailpipe and evaporative emissions of i-butane contribute $16 \%$ and $28 \%$, respectively, to the total VOC emissions from LPG vehicles, and $17 \%$ and $21 \%$ of n-butane.

Good agreement between 2-methylpentane: 3methylpentane ambient, vehicle chase and literature ratios implicate vehicle exhaust emissions as the primary 
source of these VOCs in the Mexico City atmosphere. For the other alkane pairs listed in Table 6, agreement between ambient and vehicle exhaust ratios was not as good. The ambient ratios generally followed the vehicular emissions line, but with considerable scatter. This suggests that species such as isopentane, $\mathrm{n}$-pentane, hexane, cyclohexane, $\mathrm{n}$-heptane, $\mathrm{n}$-nonane and n-octane are emitted by vehicles, but also by a variety of other anthropogenic sources.

As illustrated in Fig. 9, the ratios of i-propylbenzene and styrene with other aromatics displayed significant scatter suggesting the importance of non-vehicle anthropogenic sources, such as industries and trash burning, for these two VOCs. The xylenes showed excellent agreement with vehicle exhaust ratios, in fact they showed the best agreement among all correlated VOCs, indicating clearly that their source is vehicle exhaust. The ethylbenzene:toluene average ratios from vehicle exhaust and ambient measurements agreed quite well although there was more scatter in the data. The toluene versus benzene ratio violates the assumption of similar $\mathrm{OH}$ reactivity, but is shown to illustrate the variability. It varied from 3.5 at rural sites to 8.1 at the industrial site. The geometric mean ratio at urban sites determined from the canisters (5.1) was similar to that determined by research grade DOAS at CENICA (5.5) and the ratio published by Bravo et al. (2002) for residential areas of Mexico City (4.8). A number of mobile-lab and DOAS measurements of toluene were not correlated with elevated $\mathrm{CO}_{2}$ concentrations, indicating non-combustion sources.

Another method of comparing the ambient data to the roadway vehicle exhaust signature is to compare ratios using a tracer species as a reference. In this case, we compared hydrocarbon abundances relative to acetylene since acetylene is known to be a good marker for vehicular fuel combustion (Barletta et al., 2002). The use of ratios compresses the large differences in concentration that exist between the various environments and provides a direct comparison of hydrocarbon distribution patterns. To eliminate changes in the ratio due to photochemical aging, the ambient data were restricted to the morning period between 6:00 and 9:00 h. Figure 10 shows the median values of the VOC/acetylene ratios together with the 10th and 90th percentile ranges. A good correlation can be seen between vehicle exhaust and ambient ratios at urban sites with all exhaust ratios falling within the 10-90 percentile confidence interval. Species with the highest $\mathrm{OH}$ reactivity showed larger deviations from the exhaust ratio suggesting that, even in samples collected during the early morning hours, a chemical aging bias may affect the data. Reactive species such as 1,3butadiene, isoprene, 1-pentene, 1,2,4-trimethylbenzene and 1,3,5-trimethylbenzene had median ratios that were between 30 and $45 \%$ of the exhaust values. For example, while the abundances of 1,3-butadiene and 1,3,5-trimethylbenzene relative to acetylene at urban sites were 31 and $44 \%$ those of the on-road vehicle emission samples, the ambient MTBE and toluene ratios with acetylene agreed well with the ex- haust ratio. This would support a chemical age argument because 1,3-butadiene and 1,3,5-trimethylbenzene are about ten times more reactive with $\mathrm{OH}$ than MTBE and toluene. It is important to highlight that the $\mathrm{C}_{2}-\mathrm{C}_{4}$ alkanes (ethane, propane, i-butane and n-butane), and ethyl acetate showed higher ratios compared to exhaust values at urban sites. This is what would be expected if other anthropogenic sources contribute to low molecular weight alkane emissions. All olefin and aromatic ratios were lower than the vehicle chase ratios, which is consistent with an ageing bias. Interestingly, the 90th percentile ambient ratio boundary agrees very well with the vehicle chase ratio. The 90th percentile data perhaps reflects fresher emissions and less aging bias.

\subsection{Comparison of ambient VOC concentrations to the emissions inventory}

The ambient VOC data can be compared to the distribution of VOC classes represented in the most recent emissions inventory derived for air quality modeling in Mexico City (West et al., 2004). This emissions inventory was based on annual emissions reported in 1998 (CAM, 2001). The official inventory was created by local government authorities using bottom-up methods and emissions factors which were either measured locally or taken from elsewhere. The VOC speciation was based on the SAPRC-99 chemical mechanism for VOC reactivity assessment (Carter, 2000) and a standard mixture of hydrocarbons in urban atmospheres in the United States (Jeffries et al., 1989). The speciation was determined for each source category using emissions profiles measured in Mexico City (Mugica et al., 1998, 2002b; Vega et al., 2000). These profiles were adjusted to include species and source categories not measured in Mexico City using emissions profiles from the SPECIATE database (USEPA, 1993).

The median VOC ambient data from MCMA-2002 and 2003 are lumped into the inventory modeling classes in Table 7. For comparison, the total emissions by each class are also included in the table along with the corresponding percentage of the total. The comparison was limited to the morning period between 6:00 and 9:00 $\mathrm{h}$ when concentrations are strongly related to anthropogenic emissions before the photochemistry occurs. The column showing the adjustment factor, which takes into account the molecular weight of each class, reflects the degree of change needed to yield the same distribution in the emissions inventory as observed in ambient VOC concentrations. This comparison of early morning ambient data and gridded total emissions suggests that some, but not all, classes are underestimated in the inventory by factors of 1.1 to 3.1, in contrast to other species that are overestimated, such as some aromatic and olefin classes (ARO1, $\mathrm{ARO} 2$, OLE1 and OLE2). The extreme adjustment factors of 10.8 and 0.05 for butadiene and isoprene, respectively, are due to their small ambient concentrations compared to other VOC classes. Overall, the emissions inventory appears to underestimate the contribution of alkanes and overestimates 


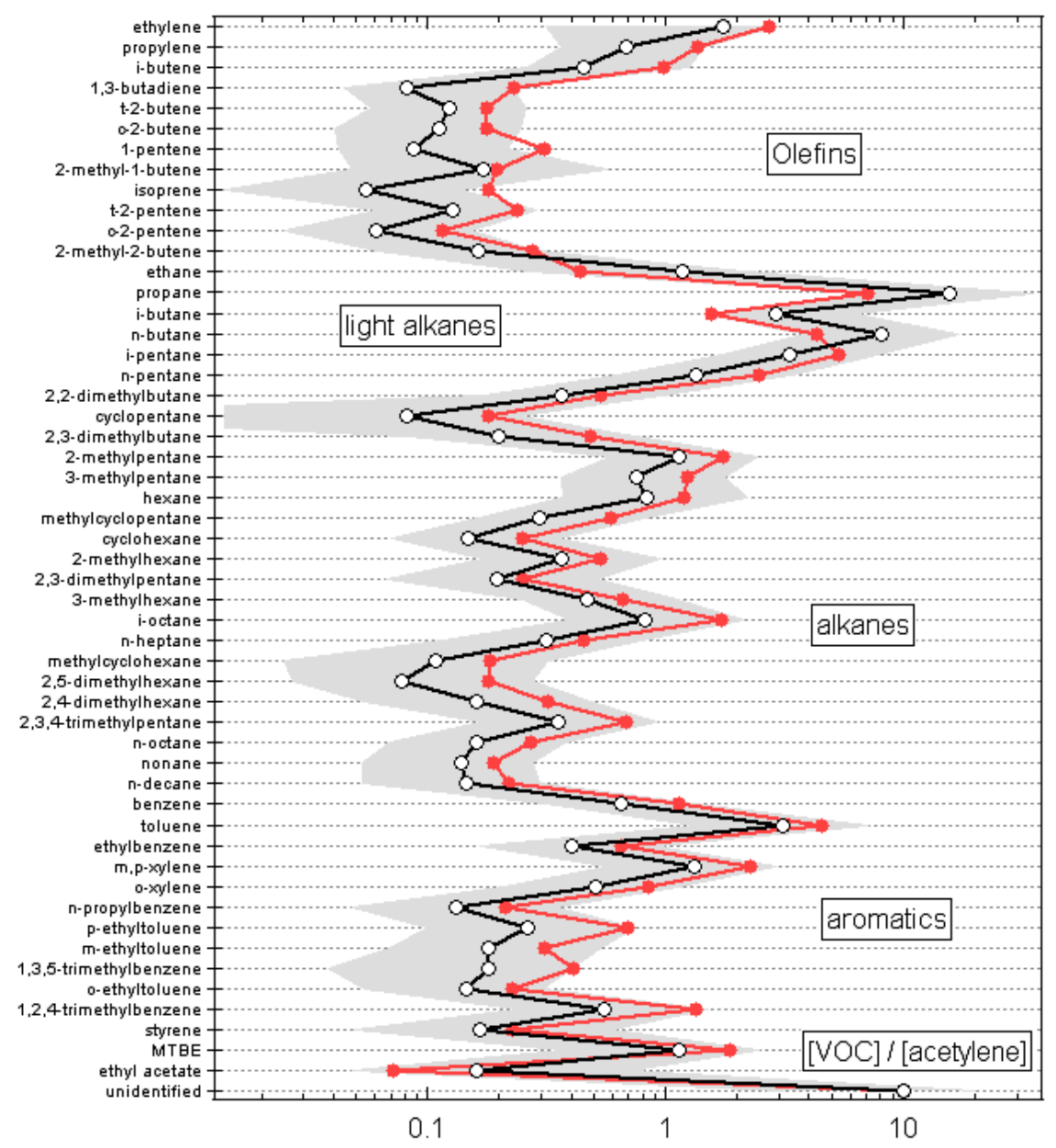

Fig. 10. Comparison of urban and vehicle exhaust hydrocarbon abundances relative to acetylene in (ppbC/ppbC). The closed circles indicate the median values for vehicle exhaust, while the open circles indicate the median values for urban data collected from urban sites (Pedregal, La Merced and CENICA) between 6 and 9:00 h. The gray shading encloses the 10th and 90th percentiles of the urban values.

the contributions of olefins and aromatics. These results do not support the idea that all VOC emissions reported in the official inventory are underestimated by a factor of 3 (Arriaga et al., 2004; West et al., 2004), however this is a relatively simplistic comparison that does not fully account for the spatial and temporal distribution of emissions, the small number of monitoring sites, or for any early morning chemistry that might affect the ambient levels. There is also 5 year difference between the base period for the emissions inventory and the time when these ambient measurements were taken. Lei et al. (2006) adjusted recently the speciated VOC emissions inventory of Mexico City through comparisons of VOC concentrations modeled with the Comprehensive Air Quality Model with extensions (CAMx) and the concentrations measured at the CENICA site in 2003 by canisters and DOAS. Overall, their results were consistent with the scaling factors presented here, where not all VOC species are underestimated by factors of 2 to 3 . They found that the total VOC emissions are underestimated by $\sim 65 \%$.
5.6 Comparison of olefin concentrations measured by FOS to olefin concentrations calculated by the CIT model

The high resolution and continuous data from instruments such as the FOS provide a basis for comparison with grid model simulations of selected VOCs. For example, results are shown in Fig. 11 for olefin mixing ratios measured at the CENICA site during the MCMA-2003 field campaign by FOS and modeled with the California Institute of Technology (CIT) airshed model. This model was used by West et al. (2004) to model ozone photochemistry in Mexico City. The same model set-up, including a factor of 3 increase in VOC emissions and factor of 2 increase in $\mathrm{CO}$ emissions, was used to forecast photochemistry during the MCMA2003 study based on MM5 meteorological simulations. Concentrations of ethylene, isoprene, and groups OLE1 and OLE2 in the CIT model were weighted according to their contribution to the hydrocarbon mix used by the SAPRC99 chemical mechanism and their corresponding FOS response factor. 
Table 7. Comparison between ambient VOC concentrations measured at urban sites during the morning period (6:00 to 9:00 h) and the corresponding VOC emissions from the most recent emissions inventory for modeling purposes.

\begin{tabular}{lccccc}
\hline Model species & $\begin{array}{c}\text { Ambient [VOC] } \\
(\mathrm{ppbC})^{1}\end{array}$ & \% of total & $\begin{array}{c}\text { Inventory } \times 10^{3} \\
\text { (tons/yr) }\end{array}$ & $\begin{array}{c}\text { \% of inventory } \\
\text { in C moles }\end{array}$ & $\begin{array}{c}\text { Adjustment factor to } \\
\text { correct the inventory }\end{array}$ \\
\hline ETHANE & 29.7 & 2.3 & 3.3 & 1.0 & 2.3 \\
PROPANE & 339.5 & 25.7 & 50.1 & 15.1 & 1.7 \\
ALK1 & 470.8 & 35.7 & 36.2 & 11.7 & 3.1 \\
ALK2 & 91.5 & 6.9 & 78.3 & 22.5 & 0.3 \\
ACETYLENE & 24.3 & 1.8 & 4.2 & 1.4 & 1.3 \\
ETHYLENE & 37.3 & 2.8 & 7.9 & 2.50 & 1.1 \\
OLE1 & 29.5 & 2.2 & 15.8 & 5.2 & 0.4 \\
OLE2 & 20.8 & 1.6 & 22.9 & 7.5 & 0.2 \\
BUTADIENE & 1.9 & 0.2 & 0.04 & 0.01 & 10.8 \\
ISOPRENE & 1.8 & 0.1 & 7.8 & 2.5 & 0.05 \\
BENZENE & 17.2 & 1.3 & 3.3 & 1.1 & 1.1 \\
ARO1 & 95.5 & 7.2 & 40.1 & 13.0 & 0.6 \\
ARO2 & 127.5 & 9.7 & 42.8 & 13.1 & 0.7 \\
MTBE & 31.5 & 2.4 & 12.7 & 3.2 & 0.8 \\
Total & 1318.8 & 100.0 & 325.5 & 100.0 & \\
\hline
\end{tabular}

1 Ambient concentrations measured during the MCMA-2002 and 2003 field campaigns.

${ }^{2}$ From West et al. (2004).

The modeled concentrations follow the measured concentrations relatively well. This result was unexpected because of all the assumptions and uncertainties involved in the model and the FOS response. An evaluation of the fractional error defined by

Fractional Error $=\frac{1}{N} \sum_{i=1}^{N} \frac{\left|\left(c_{m_{i}}-c_{o_{i}}\right)\right|}{\frac{1}{2}\left(c_{m_{i}}+c_{o_{i}}\right)}(100 \%)$,

where $c_{m}$ and $c_{o}$ represents the modeled and measured concentrations, respectively, showed a median error of $51 \%$ for the entire MCMA-2003 field campaign. During the daytime $(6: 00-19: 00 \mathrm{~h})$ the fractional error was smaller than at night (19:00-6:00 h), 48\% versus 56\%. Figure 11a shows periods when modeled and measured levels matched very well (day 105), and other periods when the FOS reported higher or lower concentrations than the model. In general, the model tends to underpredict concentrations at night and to overpredict during the daytime. Figure $11 \mathrm{~b}$ shows that the major discrepancy occurs during rush hours when the model overpredicts the morning peak. This peak is predicted by the model to occur one hour later than observed in the ambient measurements. Overall, the estimated olefin concentrations are in good agreement with the measured concentrations, since modeled concentrations are within one standard deviation of the measured concentrations.

While this would seem to support the factor of three hypothesis, it is known that this setup of CIT has excessive vertical mixing (de Foy, personal communications). Compensating errors could be responsible for this agreement and need to be investigated further in proposing refinements to the emissions inventory.

\section{Summary and conclusions}

A number of independent methods were used to measure ambient VOC concentrations in the Valley of Mexico during the MCMA 2002 and 2003 field campaigns. The use of different techniques allowed a wide range of individual species to be measured with different spatial and temporal scales, providing confidence in the data, as well as a basis for comparison with grid model simulations of selected VOCs. The VOC concentrations were analyzed to understand better their distribution, diurnal pattern, origin and reactivity in the atmosphere of Mexico City. The following points summarize the main findings and conclusions of this work.

- Despite some differences between GC-FID, PTRMS and DOAS measurements, ambient air intercomparisons for selected VOCs showed good agreement. This was true in spite of the fact that GC-FID and PTR-MS consisted of point measurements while the DOAS measured over a long path. An exception was the benzene measurements by DOAS, which differ from PTR-MS and GC-FID measurements in the early afternoon, when ozone concentrations are high.

- At urban sites, the ambient concentration of VOCs depends strongly on the interaction of vehicular activity and meteorological processes. At La Merced and 


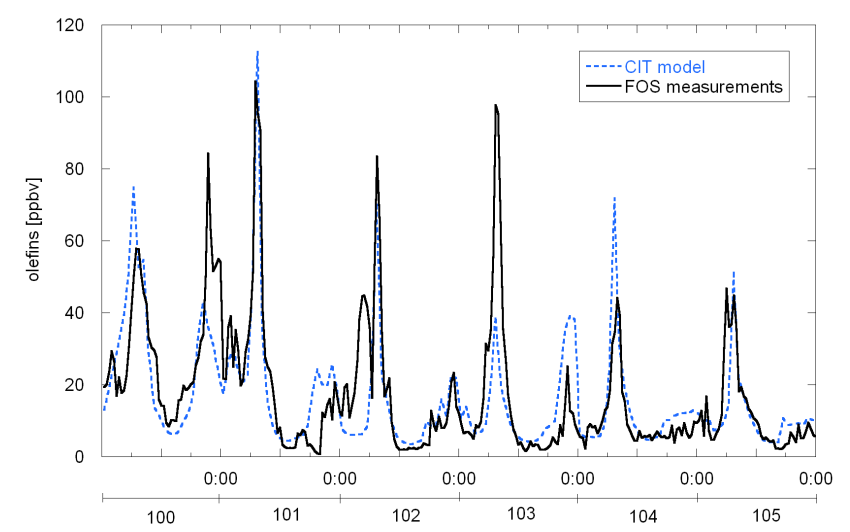

(a)

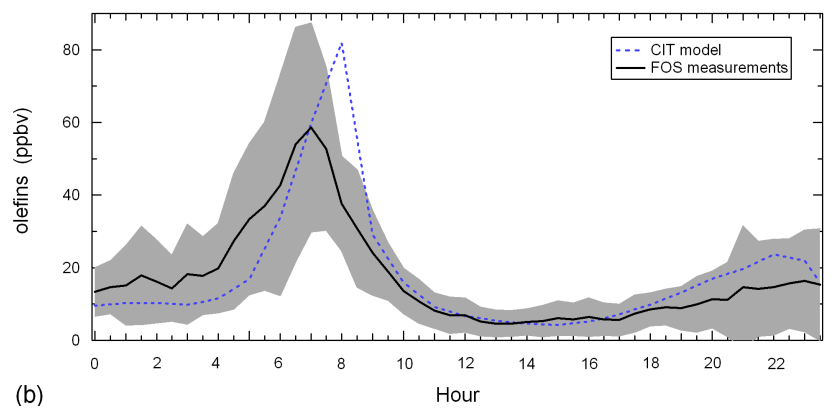

Fig. 11. Olefins concentration measured by the FOS and calculated by the CIT model considering an increment factor of 3 in VOC emissions (a) during 5 days and (b) average concentrations measured during the entire MCMA-2003 field campaign at the CENICA site. The gray shading indicates the \pm 1 standard deviation range from the FOS measurements.

CENICA, no late afternoon peak in VOC concentration was observed, while at the Pedregal site the morning and late afternoon VOC peaks were observed.

- At boundary sites, the diurnal profiles of ambient VOC concentrations depend mainly on wind patterns with evidence of transport of the urban plume. These sites correspond to rural landscapes, where burning of agriculture debris and trash is common. Biomass and trash burning was observed to produce spikes on ambient concentrations of selected VOCs, such as styrene.

- In general, VOC concentrations reported here are smaller than concentrations reported in the 1990s. This finding is consistent with Arriaga et al. (2004), who state that ambient VOC concentrations have stabilized and possibly decreased. This is a good indicator that enacted policies and actions to control VOC emissions have shown success, despite the growth in the vehicular fleet and other activities.

- In the morning, the entire valley experiences a relatively homogeneous mix of VOCs consisting of $\sim 60 \%$ alkanes, $\sim 15 \%$ aromatics, $\sim 5 \%$ olefins and a remaining
$20 \%$ of unidentified VOCs (alkynes, halogenated hydrocarbons, oxygenated species, etc.), based on ppbC. In the afternoon, concentrations are lower and the distribution among species is different with a higher contribution of unidentified VOCs at the urban sites.

- In terms of $\mathrm{OH}$ reactivity, olefins are the hydrocarbons of major concern in Mexico City. Ethylene and propylene are the two most reactive VOCs with $\mathrm{OH}$ in the atmosphere of Mexico City. The elevated concentrations of propane and n-butane are sufficient to rank these two alkanes among the top $5 \mathrm{VOCs}$, even though their reactivity rate coefficients are small compared to those for olefins and aromatics.

- Elevated levels of toxic VOCs, such as 1,3-butadiene, vinyl chloride and the BTEX hydrocarbons were observed. These VOCs are of public health concern.

- The ratios of ambient and on-road exhaust enriched concentrations between two hydrocarbons with similar photochemical lifetimes and the ratios of different VOCs with acetylene (an automotive exhaust transfer) demonstrated that many olefins and aromatics have their main origin in vehicle exhaust, such as the xylenes, toluene, ethylbenzene, t-2-pentene, c-2-pentene, etc., as well as MTBE and some alkanes, such as 2-methylpentane and 3-methylpentane. The ratios with acetylene showed that vehicle exhaust contributes to the emission of nearly all VOC species classes, including light molecular weight alkanes that have been widely related with the use of residential LPG, particularly propane and n-butane.

- Examination of the VOC data in terms of the relative distribution of lumped modeling VOC classes and comparison to the emissions inventory suggests that the inventory underestimates the contribution of some alkanes and overestimates the contributions of some olefins and aromatics.

- The comparison between ambient concentrations of olefins measured by FOS and olefins predicted by the CIT model using a VOC emission inventory increased by a factor of three showed relatively good agreement. However, we reported separately (Velasco et al., 2005) that the fluxes of olefins appeared to agree with the VOC emissions without any adjustment. The difference in these contradictory results may be due to errors in atmospheric mixing in the modeling process.

Although some pollutants have been successfully controlled in Mexico City during the last decade, concentrations for other pollutants are still elevated, including the VOC discussed in this manuscript. Effective control strategies to reduce ambient VOC concentrations need to consider both the VOC reactivity in terms of production of ozone and other secondary pollutants, and the toxic potential. These control 
strategies must be focused in improving fuels quality and vehicle technology, inspection and maintenance, since there is strong evidence that vehicle exhaust is the main source of many hydrocarbons. However, they are not going to solve by themselves the air pollution problem in Mexico. Fossil fueled private cars cannot continue being the main transport mode, new types of public and private transport with lower environmental impacts need to be implemented to decrease the use of fossil transportation fuels. One promising example is the system of buses confined to isolated lanes on main avenues, simulating subways lines above the surface, including the recently initiated "Metrobus system" in Mexico City (FIMEVIC, 2006), resulting in reduced travel duration and improved air quality, while decreasing private vehicle use.

Acknowledgements. This study was supported by the Integrated Program on Urban, Regional and Global Air Pollution from the Massachusetts Institute of Technology (MIT) and the Metropolitan Commission of Environment of Mexico City (CAM). The authors thank the assistance of the National Center for Environmental Research and Training (CENICA) of the National Institute of Ecology of Mexico (INE), as well as the assistance of the Atmospheric Monitoring System of the Federal District Government (SIMAT). Data analysis funding from the National Science Foundation (Grant \#ATM-0528170 and ATM-0528227) and the Department of Energy (Grant \#DE-FG02-05ER63982 and DE-FG02ER3980) to Aerodyne Research and MIT is acknowledged. R.V. acknowledges consecutive fellowships by Henry and Camille Dreyfus Foundation and Alexander von Humboldt Foundation. Finally, the authors wish to thank the anonymous reviewers who provided very helpful comments for the final manuscript.

Edited by: U. Pöschl

\section{References}

Arriaga, J. L., Escalona, S., Cervantes, A. D., Orduñez, R. and Lopez, T.: Seguimiento de COV en aire urbano de la ZMCM 1992-1996, in: Contaminación Atmosférica, Vol. 2, edited by: Colin L. G. and Varela J. R., UAM, Mexico, 1997.

Arriaga-Colina, J. L., West, J. J., Sosa, G., Escalona, S. S., Orduñez, R. M., and Cervantes, A. D. M.: Measurements of VOCs in Mexico City (1992-2001) and evaluation of VOCs and CO in the emissions inventory, Atmos. Environ., 38, 2523-2533, 2004.

Atkinson, R.: Gas-phase tropospheric chemistry of organic compounds, J. Phys. Chem. Ref. Data, 2, 11-216, 1994.

Atkinson, R.: Gas-phase tropospheric chemistry of volatile organic compounds, J. Phys. Chem. Ref. Data, 26, 215-290, 1997.

Barletta, B., Meinardi, S., Simpson, I. J., Khwaja, H. A., Blake, D. R., and Rowland, F. S.: Mixing ratios of volatile organic compounds (VOCs) in the atmosphere of Karachi, Pakistan, Atmos. Environ., 36, 3429-3443, 2002.

Blake, D. R. and Sherwood, F.: Urban leakage of liquefied petroleum gases and its impact on Mexico City air quality, Science, 269, 953-956, 1995.

Borbon, A., Fontaine, H., Veillerot, M., Locoge, N., Galloo, J. C., and Guillermo, R.: An investigation into the traffic-related frac- tion of isoprene at an urban location, Atmos. Environ. 35, 37493760, 2001.

Bravo, H., Sosa, R., Sanchez, P., Bueno, E., and Gonzalez, L.: Concentration of benzene and toluene of the southwestern area at the Mexico City Metropolitan Zone, Atmos. Environ., 36, 38433849, 2002.

Carter, W. P. L.: Development of ozone reactivity scales for volatile organic compounds, J. Air \& Waste Manage. Assoc., 44, 881899, 1994.

Carter, W. P. L.: Documentation of the SAPRC-99 Chemical Mechanism for VOC reactivity assessment, final report to California Air Resources Board, contracts 92-329 and 95-308, Calif. Air Res. Board, Sacramento, California, www.cert.ucr.edu/ carter, 2000.

CAM: Inventario de emisiones a la atmósfera, Zona Metropolitana del Valle de México, 1998, Comisión Ambiental Metropolitana, Mexico, 2001.

Conner, T. L., Lonneman, W. A., and Seila, R. L.: Transportation related volatile hydrocarbon source profiles measured in Atlanta, J. Air Waste Manage. Assoc., 45, 383-394, 1995.

Cruz-Nuñez, X., Hernandez-Solis, J. M., and Ruiz-Suarez, L. G.: Evaluation of vapor recovery systems efficiency and personal exposure in service stations in Mexico City, Sci. Total Environ., 309, 59-68, 2003.

de Foy, B., Caetano, E., Magaña, V., Zitácuaro, A., Cárdenas, B., Retama, A., Ramos, R., Molina, L. T., and Molina, M. J.: Mexico City basin wind circulation during the MCMA-2003 field campaign, Atmos. Chem. Phys., 5, 2267-2288, 2005, http://www.atmos-chem-phys.net/5/2267/2005/.

de Gouw, J. A., Goldan, P. A., Warneke, C., Kuster, W. C., Roberts, J. M., Marchewka, M., Bertman, S. B., Pszenny, A. A. P., and Keene, W. C.: Validation of proton transfer reaction-mass spectrometry (PTR-MS) measurements of gas-phase organic compounds in the atmosphere during the New England Air Quality Study (NEAQS) in 2002, J. Geophys. Res., 108, 4682-4199, 2003.

Doran, J. C. and Zhong, S.: Thermally driven gap winds into the Mexico City basin, J. Appl. Meteor., 39, 1330-1340, 2000.

Evans, J., Levy, J., Hammitt, J., Santos-Burgoa, C., and Castillejos, M.: Health benefits of air pollution control, in: Air Quality in the Mexico Megacity. An integrated assessment, edited by: Molina, L. T. and Molina M. J., Kluwer Academic Publishers, Netherlands, 2002.

Etzkorn, T., Klotz, B., Sorensen, S., Patroescu, I. V., Barnes, I., Becker, K. H., and Platt, U.: Gas-phase absorption cross sections of 24 monocyclic aromatic hydrocarbons in the UV and IR spectral ranges, Atmos. Environ., 33, 525-540, 1999.

FIMEVIC: Metrobus, sistema de transporte colectivo, www. fimevic.df.gob.mx/metrobus/default.htm, 2006.

Finlayson-Pitts, B. J. and Pitts, J. N.: Chemistry of the upper and lower atmosphere, Academic Press, USA, 2000.

Fraser, M. P., Cass, G. R., and Simoneit, B. R. T.: Gas-phase and particle-phase organic compounds emitted from motor vehicle traffic in a Los Angeles roadway tunnel, Environ. Sci. Technol., 32, 2051-2060, 1998.

Gakenheimer, R., Molina, L. T., Sussman, J., Zegras, C., Howitt, A., Makler, J., Lacy, R., Slott, R., and Villegas A.: The MCMA transportation system: mobility and pollution, in: Air Quality in the Mexico Megacity. An integrated assessment, edited by: 
Molina, L. T. and Molina M. J., Kluwer Academic Publishers, Netherlands, 2002.

Garcia, A. R., Volkamer, R., Molina, L. T., Molina M. J., Samuelson, J., Mellqvist, J., Galle, B., Herndon, S. C., and Kolb, C. E.: Separation of emitted and photochemical formaldehyde in Mexico City using a statistical analysis and a new pair of gas-phase tracers, Atmos. Chem. Phys., 6, 4545-4557, 2006, http://www.atmos-chem-phys.net/6/4545/2006/.

Gasca, J., Ortiz, E., Castillo, H., Jaimes, J. L., and Gonzalez, U.: The impact of liquefied petroleum gas usage on air Quality in Mexico City. Atmos. Environ., 38, 3517-3527, 2004.

GDF: Informe del Estado de la Calidad del Aire y Tendencias 2003 para la Zona Metropolitana del Valle de México, Dirección General de Gestión Ambiental del Aire, Mexico, 2004.

Gomez-Perales, J. E., Colvile, R. N., Nieuwenhuijsen, M. J., Fernández-Bremauntz, A., Gutiérrez-Avedoy, V. J., PáramoFigueroa, V. H., Blanco-Jiménez, S., Bueno-López, E., Mandujano, F., Bernabé-Cabanillas, R., and Ortiz-Segovia, E.: Commuters' exposure to $\mathrm{PM}_{2.5}$, $\mathrm{CO}$, and benzene in public transport in the metropolitan area of Mexico City, Atmos. Environ., 38, 1219-1229, 2004.

Grutter, M., Flores, E., Basaldud, R., and Ruiz-Suarez, L. G.: Openpath FTIR spectroscopic studies of trace gases over Mexico City, Atmos. Oceanic Opt., 16, 232-236, 2003.

Grutter, M. and Flores, E.: Air pollution monitoring with two optical remote sensing techniques in Mexico City, Proceedings of SPIE 5571, Gran Canaria, Spain, 13-16 September, 2004.

Grutter, M., Flores, E., Andraca-Ayala, G., and Baez, A.: Formaldehyde levels in downtown Mexico City during 2003, Atmos. Environ., 39, 1027-1034, 2005.

Guenther, A. and Hills, A.: Eddy covariance measurement of isoprene fluxes, J. Geophys. Res., 103, 13 145-13 152, 1998.

Herndon, S. C., Jayne, J. T., Zahniser, M. S., Worsnop, D. R., Knighton, B., Alwine, E., Lamb, B. K., Zavala, M., Nelson, D. D., McManus, J. B., Shorter, J. H., Canagaratna, M. R., Onasch, T. B., and Kolb, C. E.: Characterization of urban pollutant emission fluxes and ambient concentration distributions using a mobile laboratory with rapid response instrumentation, Faraday Discuss., 130, 327-339, 2005.

INE: Almanaque de datos y tendencias de la calidad del aire en ciudades mexicanas, INE-SEMARNAT, Mexico, 2000.

IPCS: Chemical Safety Information from Intergovernmental Organizations, www.inchem.org, 2005.

Jeffries, H. E., Sexton, K. G., Arnold, J. R., and Kale T. L.: Validation testing of new mechanisms with outdoor chamber data, Volume 2: analysis of VOC data for the CBA and CAL photochemical mechanisms, final report EPA-600/3-89-010b, Environmental Protection Agency, USA, 1989.

Jobson, B. T., Berkowitz, C. M., Kuster, W. C., Goldan, P. D., Williams, E. J., Fesenfeld, F. C., Apel, E. C., Karl, T., Lonneman, W. A., and Riemer, D.: Hydrocarbon source signatures in Houston, Texas: influence of the photochemical industry, J. Geophys. Res., 109, D24305, doi:10.1029/2004JD004887, 2004.

Kim, K. H.: Comparison of BTX measurements using a differential optical absorption spectroscopy and on-line gas chromatography system, Environ. Eng. Sci., 21(2), 181-194, 2004.

Kirchstetter, T. W., Singer, B. C., Harley, R. A., Kendall, G. R., and Chan W.: Impact of oxygenated gasoline use on California light duty vehicle emissions, Environ. Sci. Technol., 30, 661-
670, 1996.

Kolb, C. E., Herndon, S. C., Mcmanus, J. B., Shorter, J. H., Zahniser, M. S., Nelson, D. D., Jayne, J., Canagaratna, M. R., and Worsnop, D. R.: Mobile laboratory with rapid response instruments for real-time measurements of urban and regional trace gas and particulate distributions and emission source characteristics, Environ. Sci. Technol., 38, 5694-5703, 2004.

Lei, W., de Foy, B., Zavala, M., Volkamer, R., and Molina, L. T.: Characterizing ozone production in the Mexico City Metropolitan Area: a case study using a chemical transport model, Atmos. Chem. Phys. Discuss, 6, 7959-8009, 2006.

Lindinger, W., Hansel, A., and Jordan, A.: On-line monitoring of volatile organic compounds at pptv levels by means of protontransfer-reaction mass spectroscopy (PTR-MS): Medical applications, food control and environmental research, Int. J. Mass Spectrom. Ion Processes, 173, 191-241, 1998.

Meneses, F., Romieu, I., Ramirez, M., Colome, S., Kochy, F., Ashley, D., and Hernandez-Avila, M.: A survey of personal exposures to benzene in Mexico city, Archives of Environmental Health, 54, 359-363, 1999.

Molina, L. T. and Molina, M. J.: Cleaning the air: a comparative study, in: Air Quality in the Mexico Megacity. An integrated assessment, edited by: Molina, L. T. and Molina M. J., Kluwer Academic Publishers, Netherlands, 2002.

Mugica, V., Vega, E., Arriaga, J. L., and Ruiz, M. E.: Determination of motor vehicle profiles for non-methane organic compounds in the Mexico City Metropolitan Area, J. Air \& Waste Manage. Assoc., 48, 1060-1068, 1998.

Mugica, V., Vega, E., Chow, J., Reyes, E., Sanchez, G., Arriaga, J. L., Egami, R., and Watson, J.: Speciated non-methane organic compounds emissions from food cooking in Mexico, Atmos. Environ., 35, 1729-1734, 2001a.

Mugica, V., Vega, E., Sanchez, G., Reyes, E., Arriaga, J. L., Chow, J., Watson, J., and Arriaga, J. L.: Volatile organic compounds emissions from gasoline and diesel powered vehicle, Atmosfera 14, 29-37, 2001b.

Mugica, V., Vega, E., Ruiz, H., Sanchez, G., Reyes, E., and Cervantes, A.: Photochemical reactivity and sources of individual VOCs in Mexico City, in: Air pollution X, edited by: Brebbia, C. A. and Martin-Duque, J. F., WIT Press, UK, 2002a.

Mugica, V., Watson, J., Vega, E., Reyes, E., Ruiz, M. E., and Chow, J.: Receptor model source apportionment of nonmethane hydrocarbons in Mexico City, The Scientific World Journal, 2, 844860, $2002 b$.

Mugica, V., Ruiz, M. E., Watson, J., and Chow, J.: Volatile aromatic compounds in Mexico City atmosphere: levels and source apportionment, Atmosfera, 16, 15-27, 2003.

Ortiz, E., Alemon, E., Romero, D., Arriaga, J. L., Olaya, P., Guzman, F., and Rios, C.: Personal exposure to benzene, toluene and xylene in different microenvironments at the Mexico City metropolitan zone, Sci. Total Environ., 287, 241-248, 2002.

Parrish, D. D., Trainer, M., Young, V., Goldan, P. D., Kuster, W. C., Jobson, B. T., Fehsenfeld, F. C., Lonneman, W. A., Zika, R. D., Farmer, C. T., Riemer, D. D., and Rodgers, M. O.: Internal consistency tests for evaluation of measurements of anthropogenic hydrocarbons in the troposphere, J. Geophys. Res., 103, 22339 $22359,1998$.

Pinhua, X., Wenqing, L., Qiang, F., Ruibin, W., Jianguo, L., and Qingnong, W.: Intercomparison of $\mathrm{NO}_{\mathrm{x}}, \mathrm{SO}_{2}, \mathrm{O}_{3}$, and aromatic 
hydrocarbons measured by a commercial DOAS system and traditional point monitoring techniques, Adv. Atmos. Sci., 21, 211$219,2004$.

Raga, G. B., Baumgardner, D., Kok, G., and Rosas, I.: Some aspects of boundary layer evolution in Mexico City, Atmos. Environ., 33, 5013-5021, 1999.

Raga, G. B., Baumgardner, D., Castro, T., Martinez-Arroyo, A., and Navarro-Gonzalez, R.: Mexico City air quality: a qualitative review of gas and aerosol measurements (1960-2000), Atmos. Environ., 35, 4041-4058, 2001.

Reimann, S., Calanca, P., and Hofer, P.: The anthropogenic fraction contribution to isoprene concentrations in a rural atmosphere, Atmos. Environ., 34, 109-115, 2000.

Rogak, S. N., Pott, U., Dann, T., and Wang D.: Gaseous emissions from vehicles in a traffic tunnel in Vancouver, British Columbia, J. Air Waste Manage. Assoc., 48, 604-615, 1998.

Rogers, T. M., Grimsrud, E. P., Herndon, S. C., Jayne, J. T., Kolb, C. E., Allwine, E., Westberg, H., Lamb, B. K., Zavala, M., Molina, L. T., Molina, M. J., and Knighton, W. B.: On-road measurements of volatile organic compounds in the Mexico City Metropolitan Area using Proton Transfer Reaction Mass Spectrometry, Int. J. Mass Spectrom., 252, 26-37, 2006.

Sagebiel, J. C., Zielinska, B., Pierson, W. R., and Gertler, A. W.: Real world emissions and calculated reactivities of organic species from motor vehicles, Atmos. Environ., 30, 2287-2296, 1996.

Schifter, I., Diaz, L., Duran, J., Guzman, E., Chavez, O., and LopezSalina, E.: Remote sensing study of emissions from motor vehicles in the Metropolitan Area of Mexico City, Environ. Sci. Technol., 37, 395-401, 2003.

Schifter, I., Diaz, L., Lopez-Salinas, E., Rodriguez, R., Avalos, S., and Guerrero, V.: An evaluation of the LPG vehicles program in the metropolitan area of Mexico City, J. Air Waste Manage. Assoc., 50, 301-309, 2000.

Shiohara, N., Fernández-Bremauntz, A., Blanco-Jiménez, S., and Yanagisawa Y.: The commuters' exposure to volatile chemicals and carcinogenic risk in Mexico City, Atmos. Environ., 39, 3481-3489, 2005.

Shirley, T. R., Brune, W. H., Ren, X., Mao, J., Lesher, R., Cardenas, R., Volkamer, R., Molina, L. T., Molina, M. J., Lamb, B., Velasco, E., Jobson, T., and Alexander, M.: Atmospheric oxidation in the Mexico City Metropolitan Area (MCMA) during April 2003, Atmos. Chem. Phys., 6, 2753-2765, 2006, http://www.atmos-chem-phys.net/6/2753/2006/.

USEPA: Compendium method TO-14a. Determination of volatile organic compounds (VOCs) in ambient air using specially prepared canisters with subsequent analysis by gas chromatography (EPA/625/R-96/010b). Compendium of methods for the determination of toxic organic compounds in ambient air, 2nd Edition, US EPA, Cincinnati, OH, 1999a.

USEPA: Integrated Risk Information System (IRIS) on 1,3Butadiene, National Center for Environmental Assessment, Office of Research and Development, Washington, DC. 1999b.
USEPA: SPECIATE, VOC/PM speciation data system, version 1.50, Environmental Protection Agency and Radian Corporation, Research Triangle Park, N.C., 1993.

Vega, E., Mugica, M., Carmona, R., and Valencia, E.: Hydrocarbon source apportionment in Mexico City using the chemical mass balance receptor model, Atmos. Environ., 34, 4121-4129, 2000.

Velasco, E.: Estimates for biogenic non-methane hydrocarbons and nitric oxide emissions in the Valley of Mexico, Atmos. Environ., 37, 625-637, 2003.

Velasco, E., Lamb, B., Pressley, S., Allwine, E., Westberg, H., Jobson, T., Alexander, M., Prazeller, P., Molina, L., and Molina, M.: Flux measurements of volatile organic compounds from an urban landscape, Geophys. Res. Lett., 32, L20802, doi:10.1029/2005GL023356, 2005.

Volkamer, R., Etzkorn, T., Geyer, A., and Platt, U.: Correction of oxygen interference with UV spectroscopic (DOAS) measurements of monocyclic aromatic hydrocarbons in the atmosphere, Atmos. Environ., 32, 3731-3747, 1998.

Volkamer, R., Molina, L. T., Molina, M. J., Shirley, T., and Brune, W. H.: DOAS measurement of glyoxal as an indicator for fast VOC chemistry in urban air, Geophys. Res. Lett., 32, L08806, doi:10.1029/2005GL022616, 2005.

Warneke, C., de Gouw, J. A., Kuster, W. C., Goldan, P. D., and Fall, R.: Validation of atmospheric VOC measurements by proton transfer reaction mass spectroscopy using a gas chromatographic preseparation method, Environ. Sci. Technol., 37, 24942501, 2003.

Watson, J. G., Chow, J. C., and Fujita, E. M.: Review of volatile organic compound source apportionment by chemical mass balance, Atmos. Environ., 35, 1567-1584, 2001.

West, J., Zavala, M. A., Molina, L. T., Molina, M. J., San Martini, F., McRae, J., Sosa, G., and Arriaga-Colina, J. L.: Modeling ozone photochemistry and evaluation of hydrocarbon emissions in the Mexico City metropolitan area, J. Geophys. Res., 109, 19312-19327, 2004.

Whiteman, C. D., Zhong, S., Bian, X., Fast, J. D., and Doran, J. C.: Boundary layer evolution and regional-scale diurnal circulations over the Mexico Basin and Mexican plateau, J. Geophys. Res., 106(D8), 10 081-10 102, 2000.

Ye, Y., Galbally, I. E., and Weeks, I. A.: Emission of 1,3-butadiene from petrol-driven motor vehicles, Atmos. Environ. 31, 1157$1165,1997$.

Zavala, M., Herndon, S. C., Slott, R. S., Dunlea, E. J., Marr, L. C., Shorter, J. H., Zahniser, M., Knighton, W. B., Rogers, T. M., Kolb, C. E., Molina, L. T., and Molina, M. J.: Characterization of on-road vehicle emissions in the Mexico City Metropolitan Area using a mobile laboratory in chase and fleet average measurement modes during the MCMA-2003 Field Campaign, Atmos. Chem. Phys., 6, 5129-5142, 2006,

http://www.atmos-chem-phys.net/6/5129/2006/. 